NBER WORKING PAPER SERIES

\title{
PROJECTIONS AND UNCERTAINTIES ABOUT CLIMATE CHANGE IN AN ERA OF MINIMAL CLIMATE POLICIES
}

\author{
William D. Nordhaus \\ Working Paper 22933 \\ http://www.nber.org/papers/w22933 \\ NATIONAL BUREAU OF ECONOMIC RESEARCH \\ 1050 Massachusetts Avenue \\ Cambridge, MA 02138 \\ December 2016, Revised September 2017
}

The research reported here was supported by the Carnegie Commission of New York, the U.S. National Science Foundation, and the U.S. Department of Energy. The views are entirely the responsibility of the author. The author declares that he has no relevant and material financial conflicts with the research described in this paper. The views expressed herein are those of the author and do not necessarily reflect the views of the National Bureau of Economic Research.

NBER working papers are circulated for discussion and comment purposes. They have not been peer-reviewed or been subject to the review by the NBER Board of Directors that accompanies official NBER publications.

(C) 2016 by William D. Nordhaus. All rights reserved. Short sections of text, not to exceed two paragraphs, may be quoted without explicit permission provided that full credit, including () notice, is given to the source. 
Projections and Uncertainties About Climate Change in an Era of Minimal Climate Policies William D. Nordhaus

NBER Working Paper No. 22933

December 2016, Revised September 2017

JEL No. C15,F6,Q5,Q54

\begin{abstract}
$\underline{\text { ABSTRACT }}$
Climate change remains one of the major international environmental challenges facing nations. Up to now, nations have to date adopted minimal policies to slow climate change. Moreover, there has been no major improvement in emissions trends as of the latest data. The current study uses the updated DICE-2016R2 model to present new projections and the impacts of alternative climate policies. It also presents a new set of estimates of the uncertainties about future climate change and compares the results with those of other integrated assessment models. The study confirms past estimates of likely rapid climate change over the next century if major climatechange policies are not taken. It suggests that it is unlikely that nations can achieve the $2{ }^{\circ} \mathrm{C}$ target of international agreements, even if ambitious policies are introduced in the near term. The required carbon price needed to achieve current targets has risen over time as policies have been delayed.
\end{abstract}

William D. Nordhaus

Yale University, Department of Economics

28 Hillhouse Avenue

Box 208264

New Haven, CT 06520-8264

and NBER

william.nordhaus@yale.edu

A data appendix is available at http://www.nber.org/data-appendix/w22933 


\section{Introduction}

\section{Background}

Climate change remains the central environmental issue of today. While the Paris Agreement on climate change of 2015 (Paris Agreement 2016) has recently been ratified, it is limited to voluntary emissions reductions for major countries, and the United States has withdrawn. No binding agreement for emissions reductions is currently in place following the expiration of the Kyoto Protocol in 2012. Countries have agreed on a target temperature limit of $2{ }^{\circ} \mathrm{C}$, but this is far removed from actual policies, and is probably infeasible, as will be seen below. The reality is that most countries are on a business-as-usual (BAU) trajectory of minimal policies to reduce their emissions, taking non-cooperative policies that are in their national interest, but far from ones which would represent a global cooperative policy.

Given the realities of actual climate policies, it is critical to determine the trajectory the world is on now, or what the BAU involves. The most recent IPCC report (IPCC Fifth Assessment Report, Science, 2013) ignores the BAU; instead, it examines stylized trajectories that are only loosely related to actual policies, output, and emissions paths. It would be difficult, reading the most recent IPCC reports, to determine the likely outcome for future climate change and damages in an unregulated policy space.

The present study attempts to fill this void by investigating in detail the implications of a world in the absence of ambitious climate policies. It does so with a newly revised model, the DICE-2016R2 model (DICE stands for Dynamic Integrated model of Climate and the Economy). In addition to standard runs, the current study adds a new dimension by investigating the impact of uncertainties about several important parameters. The results confirm and even strengthen earlier results, indicating the high likelihood of rapid warming and major damages if policies continue along the unrestrained path.

The methods here employ an approach known as integrated assessment models (IAMs). These are approaches to the economics of climate change that integrate the different elements into a single interrelated model. The present study presents the results of a fully revised version of the DICE model (as of 2016). This is the first major revision of the model following the Fifth Assessment Report of the IPCC. This study describes the changes in the model from the last round, presents updated estimates of the different variables, and compares the new estimates with other models. In addition, the analysis provides uncertainties in the projections using new estimates of the underlying uncertainties of major model parameters. 


\section{Overview of results}

I will not attempt to summarize the entire paper here, but will instead provide some highlights. The first result is that the revised DICE model shows more rapid growth of output in the baseline or "no-policy" path compared to earlier DICE versions and most other models. This is also reflected in a major upward revision in the social cost of carbon (SCC) and the optimal carbon tax in the current period. For example, the estimate of the SCC has been revised upwards by about $50 \%$ since the last full version in 2013. There are several components of this change - some of methods and some of data - but the change is not encouraging.

A second result is that the international target for climate change with a limit of $2{ }^{\circ} \mathrm{C}$ appears to be infeasible with reasonably accessible technologies - and this is the case even with very stringent and unrealistically ambitious abatement strategies. This is so because of the inertia of the climate system, of rapid projected economic growth in the near term, and of revisions in several elements of the model. A target of $2 \frac{1}{2}{ }^{\circ} \mathrm{C}$ is technically feasible but would require extreme and virtually universal global policy measures.

A third point is to emphasize that this study focuses on the business-as-usual trajectory, or the one that would occur without effective climate policies. The approach of studying business as usual has fallen out of favor with analysts, who concentrate on temperaturelimiting or concentration-limiting scenarios. A careful study of minimal-policy scenarios may be depressing, but it is critical in the same way a CT scan is essential for a cancer patient. Moreover, notwithstanding what may be called "The Rhetoric of Nations," there has been little progress in taking strong policy measures. For example, of the six largest countries or regions, only the EU has implemented national climate policies, and the policies of the EU today are very modest (about $\$ 6 / \mathrm{tCO}_{2}$ in 2017). Moreover, from the perspective of political economy in different countries as of summer 2017, the prospects of strong policy measures appear to be dimming rather than brightening.

The paper also investigates the implications of uncertainty for climate change. When uncertainties are accounted for, the expected values of most of the major geophysical variables, such as temperature, are largely unchanged. However, the social cost of carbon (SCC) is higher (by about 15\%) under uncertainty than in the best-guess case because of the asymmetry in the impacts of uncertainty on the damages from climate change. Note as well that even under highly "optimistic" outcomes (i.e., ones that have the most favorable realizations of the uncertain variables) global temperature increases markedly, and there are significant damages.

An additional important finding is that the relative uncertainty is much higher for economic variables than for geophysical variables. More precisely, the dispersion of results (measured, say, by the coefficient of variation (standard deviation relative to the mean) is 
larger for emissions, output, damages, and the SCC than for concentrations or temperature. This result is primarily because of the large uncertainty about economic growth. From a statistical point of view, uncertainty about most geophysical parameters is a level uncertainty and is roughly constant over time; whereas the uncertainty of economic variables is a growth-rate uncertainty and therefore tends to grow over time. By the year 2100, this implies a greater uncertainty for economic variables. Note as well that the output uncertainty implies a substantial difference between deterministic and uncertain cases.

This study makes one further important point about uncertainty. It shows that there is substantial uncertainty about the path of climate change and its impacts. The ranges of uncertainty for future emissions, concentrations, temperature, and damages are extremely large. However, this does not reduce the urgency of taking strong climate-change policies today. When taking uncertainties into account, the strength of policy (as measured by the social cost of carbon or the optimal carbon tax) would increase, not decrease.

As a final point, I emphasize that many uncertainties remain. Analysts do not know, and are unlikely soon to know, how the global economy or energy technologies will evolve; or what the exact response of geophysical systems will be to evolving economic conditions; or exactly how damaging climate change will be for the economy as well as non-market and non-human systems. We also do not know with precision how to represent the different systems in our economic and scientific models. The best practices have evolved over time as we learn more about all these systems. But we must take stock of what is known as well as the implications of our actions. The bottom line here is that this most recent taking stock has more bad news than good news, and that the need for policies to slow climate change are more pressing and not less pressing.

\section{The Structure of the DICE-2016R2 Model}

The analysis begins with a discussion of the DICE-2016R2 model, which is a revised version of the DICE-2013R model (see Nordhaus 2014, Nordhaus and Sztorc 2013 for a detailed description of the earlier version). It is the latest version of a series of models of the economics of global warming developed at Yale University by Nordhaus and colleagues. The first version of the global dynamic model was published in Nordhaus (1992). The discussion explains the major modules of the model, and describes the major revisions since the 2013 version. The current version of the DICE-2016R2 is available at http://www.econ.yale.edu/ nordhaus/homepage/DICEmodels09302016.htm.

The DICE model views climate change in the framework of economic growth theory. In the Ramsey-Koopmans-Cass optimal growth model, society invests in capital goods, thereby 
reducing consumption today in order to increase consumption in the future. The DICE model modifies the Ramsey model to include climate investments, which are analogous to capital investments in the standard model. The model contains all elements, from economics through climate change, to damages and abatement, in a structure that attempts to represent simplified best practices in each area.

\section{Equations of the DICE-2016R2 model $^{2}$}

Most of the analytical background is similar to that in the 2013R model, and for details readers are referred to Nordhaus and Sztorc (2013). Major revisions are discussed as the equations are described.

\section{Economic sectors}

The model optimizes a social welfare function, $W$, which is the discounted sum of the population-weighted utility of per capita consumption. The notation here is that $V$ is the instantaneous social welfare function, $U$ is the utility function, $c(t)$ is per capita consumption, and $L(t)$ is population. Time is in five-year periods, so $t=1$ for 2015 (2013-2017), and so forth. The discount factor on welfare is $R(t)=(1+\rho)^{-t}$, where $\rho$ is the pure rate of social time preference or generational discount rate on welfare.

(1) $W=\sum_{t=1}^{T \text { max }} V[c(t), L(t)] R(t)=\sum_{t=1}^{T \text { max }} U[c(t)] L(t) R(t)$

The utility function has a constant elasticity with respect to per capita consumption of the form $U(c)=c^{1-\alpha} /(1-\alpha)$. The parameter $\alpha$ is interpreted as generational inequality aversion, which measures the relative importance of consumption levels at different times. In the present version, the utility discount rate is $1.5 \%$ per year and the rate of inequality aversion is 1.45 . As described below, these parameters are set to calibrate real interest rates in the model.

Net output is gross output reduced by damages and abatement costs:

(2) $Q(t)=\Omega(t)[1-\Lambda(t)] Y(t)$

\footnotetext{
${ }^{2}$ The equations and description in Section II are included for reference so that readers can refer to the latest model version and revisions. These have been published in slightly different form in earlier publications, such as Nordhaus $(2013,2017)$.
} 
In this specification, $Q(t)$ is output net of damages and abatement, $Y(t)$ is gross output, which is a Cobb-Douglas function of capital, labor, and technology. The variables $\Omega(t)$ and $\Lambda(t)$ are the damage function and abatement cost and are defined below. Total output is divided between total consumption and total gross investment. Labor is proportional to population, while capital accumulates according to an optimized savings rate.

The current version develops global output in greater detail than earlier versions. The global output concept is PPP (purchasing power parity) as measured by the International Monetary Fund. The growth concept is the weighted growth rate of real GDP of different countries, where the weights are the country shares of world nominal GDP using current international US dollars. I constructed a new version of world output, and this corresponds closely to the IMF estimate of the growth of real output in constant international (PPP) dollars. The earlier model used the World Bank growth figures, but the World Bank growth rates by region could not be replicated.

The present version substantially updates both the historical growth estimates and the projections of per capita output growth. Future growth is based largely on a survey of experts conducted by Christensen et al. (2016). Growth in per capita output over the 1980 - 2015 period was 2.2\% per year. Growth in per capita output from 2015 to 2050 is now projected at $2.1 \%$ per year, while that to 2100 is projected at $1.9 \%$ per year. The revisions now incorporate the latest output, population, and emissions data and projections. Population data and projections through 2100 are from the United Nations. $\mathrm{CO}_{2}$ emissions are from the Carbon Dioxide Information Analysis Center (CDIAC), and updated using various sources. Non- $\mathrm{CO}_{2}$ radiative forcings (that is, the impact of other gases on warming) for 2010 and projections to 2100 are from projections prepared for the IPCC Fifth Assessment.

The additional variables in equation (2) above are $\Omega(t)$ and $\Lambda(t)$, which represent the damage function and the abatement-cost function, respectively. The abatement cost function, $\Lambda(t)$ in equation (2) above, is the fraction of output devoted to reducing $\mathrm{CO}_{2}$ emissions (perhaps 3\%). It was recalibrated to the abatement cost functions of other IAMs as represented in the modeling uncertainty project (MUP) study (Gillingham et al. 2015). The resulting abatement function has slightly higher costs than earlier estimates. The abatement-cost function takes the form $\Lambda(t)=\theta_{1}(t) \mu(t)^{\theta_{2}}$, where $\theta_{1}(t)=0.0741 \mathrm{x} .0904^{(t-1)}$ and $\theta_{2}=2.6$. The interpretation here is that at zero emissions for the first period, abatement is $7.41 \%$ of output. That percentage declines at $2 \%$ per year. The abatement-cost function is highly convex, reflecting the sharp diminishing returns to reducing emissions.

The model assumes the existence of a "backstop technology," which is a technology that produces energy services with zero GHG (greenhouse gas) emissions $(\mu=1)$. The backstop 
price in 2020 is $\$ 550$ per ton of $\mathrm{CO}_{2}$-equivalent, and the backstop cost declines at $1 / 2 \%$ per year. Additionally, it is assumed that there are no "negative emissions" technologies initially, but that negative emissions are available after 2150 . The existence of negative-emissions technologies $(\mu>1)$ is critical to reaching low-temperature targets, as described below.

The damage function is defined as $\Omega(t)=1-D(t)$, where ${ }^{3}$

(3) $D(t)=\psi_{1} T_{A T}(t)+\psi_{2}\left[T_{A T}(t)\right]^{2}$

Equation (3) describes the economic impacts or damages of climate change. The DICE-2016R2 model takes globally averaged temperature change $\left(T_{A T}\right)$ as a sufficient statistic for damages. Equation (3) assumes that damages can be reasonably well approximated by a quadratic function of temperature change. The estimates of the coefficients of the damage function are explained below.

Uncontrolled industrial $\mathrm{CO}_{2}$ emissions are given by a level of carbon intensity or the $\mathrm{CO}_{2}$ output ratio, $\sigma(t)$, times gross output. Total $\mathrm{CO}_{2}$ emissions, $E(t)$, are equal to uncontrolled emissions reduced by the emissions-reduction rate, $\mu(t)$, plus exogenous land-use emissions.

(4) $\quad E(t)=\sigma(t)[1-\mu(t)] Y(t)+E_{\text {Land }}(t)$

The model has been revised to incorporate a more rapid decline in the $\mathrm{CO}_{2}$-output ratio (or what is called decarbonization) to reflect the last decade's observations. The decade through 2010 showed relatively slow global decarbonization, with the global $\mathrm{CO}_{2}$-output ratio changing at $-0.8 \%$ per year. However, the most recent data indicate a sharp downward tilt, with the global $\mathrm{CO}_{2} / \mathrm{GDP}$ ratio changing at $-2.1 \%$ per year over the 2000-2015 period (preliminary data). It appears that changes in the global decarbonization rate are largely driven by China's performance rather than any significant change in the rest of the world. ${ }^{4}$ For the DICE model, it is assumed that the rate of decarbonization going forward is $-1.5 \%$ per year (using the IMF output concept). Figure 1 shows the global trend in the $\mathrm{CO}_{2}$-GDP ratio since 1960 . Note the steeper slope (increased rate of decarbonization) in the last few years.

${ }^{3}$ In early approaches, the damage function was $\Omega(t)=D(t) /[1+D(t)]$. This earlier specification ensured that damages never exceeded output. However, the damage ratio does not approach 1 in the current projections, so the quadratic specification is preferred.

${ }^{4}$ Based on preliminary data, the rate of decarbonization of the world-less-China has not changed appreciably over the last three decades. However, when China is included, the global CO2-output ratio has declined more sharply in $2010-2016$ relative to the earlier decade. The reliability of the Chinese output and emissions data are likely to be low relative to other major countries, so the impact of the Chinese data on the global total should be treated with reservations. 


\section{Geophysical sectors}

The next set of equations represents the linkage between the economy and climate change. The geophysical equations link greenhouse-gas emissions to the carbon cycle, radiative forcings (defined below), and climate change. Equation (5) represents the equations of the carbon cycle for three reservoirs.

$$
M_{j}(t)=\phi_{0 j} E(t)+\sum_{i=1}^{3} \phi_{i j} M_{i}(t-1)
$$

The three reservoirs are $j=A T, U P$, and $L O$, which are the atmosphere, the upper oceans and biosphere, and the lower oceans, respectively. The parameters $\phi_{i j}$ represent the flow parameters between reservoirs per period. All emissions flow into the atmosphere. The 2016 version incorporates new research on the carbon cycle. Earlier versions of the DICE model were calibrated to fit the short-run carbon cycle (primarily the first 100 years). Because the new model is in part designed to calculate long-run trends, such as the impacts on the melting of large ice sheets, it was decided to change the calibration to fit the atmospheric retention of $\mathrm{CO}_{2}$ for periods up to 4000 years. Based on studies of Archer et al. (2009), the 2016 version of the three-box model does a much better job of simulating the long-run behavior of larger models with full ocean chemistry. This change has a major impact on the long-run carbon concentrations.

The next relationship is between GHG accumulations and increased radiative forcing. Radiative forcing is the heat received at the earth's surface. Increased radiative forcing is the result of higher accumulations of greenhouse gases, as is shown in equation (6).

(6) $\quad F(t)=\eta\left\{\log _{2}\left[M_{A T}(t) / M_{A T}(1750)\right]\right\}+F_{E X}(t)$

$F(t)$ is the change in total radiative forcings from anthropogenic sources such as $\mathrm{CO}_{2} . F_{E X}(t)$ is exogenous forcings, and the first term is the forcings due to atmospheric concentrations of $\mathrm{CO}_{2}$.

Forcings lead to warming according to a simplified two-level global climate model:

$$
T_{A T}(t)=T_{A T}(t-1)+\xi_{1}\left\{F(t)-\xi_{2} T_{A T}(t-1)-\xi_{3}\left[T_{A T}(t-1)-T_{L O}(t-1)\right]\right\}
$$

$$
T_{L O}(t)=T_{L O}(t-1)+\xi_{4}\left[T_{A T}(t-1)-T_{L O}(t-1)\right]
$$

In these equations, $T_{A T}(t)$ is the global mean surface temperature and $T_{L O}(t)$ is the mean temperature of the deep oceans. Large-scale ocean circulation models show that there is substantial thermal inertia in the oceans, which means that the warming of the deep oceans lags hundreds of years behind warming at the surface. 
The climate module has been revised to reflect recent earth system models. The equilibrium climate sensitivity (ECS) is based on the analysis of Olsen et al. (2012). The reasons for using this approach are provided in Gillingham et al. (2015). The final estimate is mean warming of $3.1^{\circ} \mathrm{C}$ for an equilibrium $\mathrm{CO}_{2}$ doubling. The transient climate sensitivity or TCS (sometimes called the transient climate response) is adjusted to correspond to models with an ECS of $3.1^{\circ} \mathrm{C}$, which produces a TCS of $1.7^{\circ} \mathrm{C}$.

The treatment of discounting is identical to that in DICE-2013R. I distinguish between the welfare discount rate $(\rho)$ and the goods discount rate $(r)$. The welfare discount rate applies to the well-being of different generations, while the goods discount rate applies to the return on capital investments. The former is not observed, while the latter is observed in markets. When the term "discount rate" is used without a modifier, this will always refer to the discount rate on goods.

The economic assumption behind the DICE model is that the goods discount rate should reflect actual economic outcomes. This implies that the assumptions about model parameters should generate savings rates and rates of return on capital that are consistent with observations. With the current calibration, the discount rate (or equivalently the real return on investment) averages $4 \frac{1}{4} \%$ per year over the period to 2100 . This is the global average of a lower figure for the U.S. and a higher figure for other countries, and is consistent with estimates in other studies that use U.S. data.

This specification used in the DICE model is sometimes called the "descriptive approach" to discounting. The alternative approach, used in The Stern Review and elsewhere, is called the "prescriptive discount rate." (Stern 2007) Under this second approach, the discount rate is assumed on a normative basis and determined largely independently of actual market returns on investments. A full discussion of the issues of discounting is contained in Gollier (2013), with the justification for the DICE-model treatment described in Nordhaus (2008).

\section{Impacts of revisions}

The DICE model has changed substantially since its development in Nordhaus (1992). In a parallel study, I have investigated the impacts of model and data revisions over the last quarter century (Nordhaus 2017a). That study finds that the major revisions are due to changes in the economic aspects of the model, whereas the geophysical changes have been much smaller. Particularly sharp revisions have occurred for global output, damages, and the social cost of carbon. These results suggest that the economic projections are the least precise parts of integrated assessment models and deserve much greater study than has been the case up to now, especially careful studies of long-run economic growth (to 2100 and beyond). This 
point has been emphasized in a recent report of the National Academy of Sciences (National Research Council 2017).

\section{Approach to estimating uncertainties}

\section{Background}

The "standard DICE model" uses the expected values (or what I refer to as the "best guess" or BG) of parameters such as productivity growth or equilibrium temperature sensitivity. The present study examines uncertainties about major results looking at parametric uncertainties.

Developing reliable estimates that incorporate uncertainty has proven extremely challenging on both methodological and empirical grounds (see Gillingham et al. 2015). Two major sources of uncertainty are "model uncertainty" and "structural uncertainty." The difference across models is called model uncertainty. This approach, also known as ensemble uncertainty, is convenient for estimating uncertainty because the "data," which are results of different models, are readily collected and validated. The concern is that the ensemble approach is conceptually incorrect, and that there is a degree of arbitrariness concerning the selection of studies to include in the ensemble. ${ }^{5}$

Structural or parameter uncertainty, which refers to uncertainty within models, arises from imprecision in knowledge of parameters and variables as well as uncertainty about model structure. For example, climate scientists are unsure about the response of climate to increasing greenhouse-gas forcings. The present study chiefly examines structural uncertainty focusing only on uncertainties about parameters.

It will be helpful to explain the structure of the current approach analytically. The model can be represented as a mapping from exogenous and policy variables and parameters to endogenous outcomes. A model can be written symbolically as follows:

$$
Y=H(z, \alpha, u)
$$

\footnotetext{
${ }^{5}$ Ensemble uncertainty is analytically incorrect because it calculates the dispersion as the difference in the mean values of outcomes or parameters across models. To see this point, assume that models use the same data and their structures and are identical. They will have zero ensemble uncertainty even though the actual uncertainty may be large.
} 
In this schema, $Y$ is a vector of model outputs; $z$ is a vector of exogenous and policy variables; $\alpha$ is a vector of model parameters; $u$ is a vector of uncertain parameters to be investigated; and $H$ represents the model structure (described above for the DICE model).

The first step is to select the uncertain parameters for analysis. For the present study, I have selected five variables: equilibrium temperature sensitivity (ETS); productivity growth; the damage function; the carbon cycle; and the rate of decarbonization. Each has a probability density function (PDF) with a joint distribution as $g\left(u_{1}, u_{2}, u_{3}, u_{4}, u_{5}\right)$. For this study, the distributions are assumed to be independent and are denoted as $f_{i}\left(u_{i}\right)$, which implies that $g\left(u_{1}, u_{2}, u_{3}, u_{4}, u_{5}\right)=f_{1}\left(u_{1}\right) f_{2}\left(u_{2}\right) f_{3}\left(u_{3}\right) f_{4}\left(u_{4}\right) f_{5}\left(u_{5}\right){ }^{6}$ The distribution of the uncertain parameters is then mapped into the distribution of the output variables, given schematically by $h(Y)$ as follows based on (9):

$$
h(Y)=H\left[z, \alpha, f_{1}\left(u_{1}\right) f_{2}\left(u_{2}\right) f_{3}\left(u_{3}\right) f_{4}\left(u_{4}\right) f_{5}\left(u_{5}\right)\right]
$$

I note that the discount rate is not included as an uncertain variable. The reason is that, as explained above, this reflects preferences (through the rate of time preference and inequality aversion). It might be thought that generational preferences are uncertain and might evolve differently over time. Uncertainties about preferences pose philosophical difficulties that are not easily represented in economic growth models and are therefore excluded here.

A critical decision involves how actually to calculate the mapping in equation (10) for complex systems. One standard approach is a Monte Carlo sampling of the uncertain variables, but this turns out to be computationally infeasible for the DICE model in the GAMS code given

\footnotetext{
${ }^{6} \mathrm{With}$ five uncertain variables, there are ten potential correlations. Six correlations can be set to zero by first principles. These are the correlations between economic uncertainties and geophysical uncertainties. For example, there is no reason to assume that the equilibrium climate sensitivity is correlated with productivity growth. The covariance between carbon and temperature is highly complex but has be captured in the calibration of the climate model. The three remaining covariances are among damages, TFP, and decarbonization. I find a very small negative correlation between TFP growth and decarbonization in the historical record, but there are no reliable data on the correlation between damages and the other variables. Evaluating the impact of variable correlation is on the agenda for future research.
} 
constraints. ${ }^{7}$ I have therefore discretized the distributions and performed a complete enumeration of the states of the world (SOW), as defined by the above parameters. More precisely, each of the distributions of the uncertain variables is separated into quintiles. The expected values of the uncertain variables are next calculated for each quintile, obtaining discrete values for each variable of $\left\{u_{i}(1), u_{i}(2), u_{i}(3), u_{i}(4), u_{i}(5)\right\}$, where $u_{i}(k)$ is the $k t h$ quintile of uncertain variable $i$.

There are two adjustments of the discrete distributions for present purposes. First, the middle quintile is set equal to the expected value of the parameter. This is done so that the median and mean outcomes can be easily compared. Secondly, because the first adjustment changes the means and standard deviations for the uncertain variables, the quintile values are adjusted so that the means and standard deviations are preserved. This second step involves small adjustments in the non-central quintile values.

While the algorithm for estimating uncertainty is computationally efficient, an important question involves its accuracy. If the model in (10) is linear in the uncertain parameters, the approach is exact. However, to the extent that (10) is non-linear in the parameters, the algorithm may provide biased estimates of the variability. I have tested the accuracy using an alternative approach that involves a response surface function or RSF. The basic idea is to fit a polynomial function of the uncertain variables to the 3125 grid points using a response surface function (RSF), and then estimate the distribution of the output variables using a Monte Carlo simulation. These estimates indicate that the discretized probability distributions provide an accurate representation of the distributions of the uncertain variables. The use of response surface functions is widespread in engineering systems and has been applied to complex econometric problems. See online materials, particularly part A, Table A-1, and Annex A, as well as Mizon and Hendry (1980) for an econometric example.

The actual computations involved a complete enumeration of the $5^{5}=3125$ combinations of uncertain parameters for each state of the world (SOW). This took about two hours on a high-end PC workstation.

\footnotetext{
7 The constraints are that the modeling should be replicable on a PC and use the GAMS code. A single run takes about 5 seconds. I estimate that it would require a sample of about 10 million runs to get reliable estimates using Monte Carlo techniques. GAMS software does not allow this to be done easily, and using the standard code would require about three months of computer time. Moving to other platforms would clearly speed up the computations, but this would make replication and use by other scholars more difficult. The appendix examines an alternative approach using a response surface method.
} 


\section{Determination of the probability distributions}

Five probability distributions were selected based on earlier work that suggests the most important uncertain variables (see the extensive discussion in Nordhaus 1994, 2008) as well as those in the MUP study for comparison (Gillingham et al., 2015). This section describes the derivation of the distributions.

Equilibrium temperature sensitivity (ETS). The distribution for ETS adopts the approach used in the MUP study. The primary estimates are from Olsen et al. (2012). This study uses a Bayesian approach, with a prior based on previous studies and a likelihood based on observational or modeled data. The best fitting distribution is a log-normal PDF. The parameters of the log-normal distribution fit to Olsen et al. are $\mu=1.107$ and $\sigma=0.264$. The major summary statistics of the reference distribution in the study are the following: mean $=$ 3.13 , median $=3.03$ and standard deviation $=0.843$.

Productivity growth. The scholarly literature on uncertainties about long-run economic growth is thin. The specification relied on a survey of experts conducted by a team at Yale University led by Peter Christensen (Christensen et al 2016). The survey utilized information drawn from a panel of experts to characterize uncertainty in estimates of global output for the periods 2010-2050 and 2010-2100. Growth was defined as the average annual rate of growth of global real per capita GDP, measured in purchasing power parity (PPP) terms.

The resulting estimates of growth were best fit using a normal distribution. The resulting combined normal distribution had a mean growth rate of $2.06 \%$ per year and a standard deviation of the growth rate of $1.12 \%$ per year over the period 2010-2100. The procedures and estimates will shortly be available in a working paper, and a short description is in Gillingham et al. (2015). An alternative low-frequency approach developed by Muller and Watson (2016) gives a significantly lower dispersion at long horizons (a standard deviation of approximately $0.8 \%$ per year for 2010 - 2100). For the calculations, I used the estimate from the survey.

Decarbonization. The DICE model has a highly condensed representation of the energy sector. The most important parameters are the level and trend of the global ratio of uncontrolled $\mathrm{CO}_{2}$ emissions to output, $\sigma(t)$, as shown in equation (4). This is modeled as an initial growth rate with a slow decline over time. While there are several studies that include something like this ratio (often modeled as autonomous energy efficiency improvement, AEEI), there are no consensus estimates about its uncertainty because of the differences in IAM specifications.

There are two alternative approaches to estimate uncertainty. The first examined was a time-series approach. For this, I reviewed historical data on the global emissions/output ratio. 
The simplest approach is to estimate an OLS regression, using data from 1960 to 2015, and then look at the forecast error for 2100. If an AR1 term is included in the equation, the standard error of the forecast for 2100 is $13.5 \%$ of the logarithm of $\sigma(t)$. This implies an annual uncertainty of $0.149 \%$ per year. However, a unit root of $\sigma(t)$ cannot be rejected, so this estimate is biased downward.

An alternative approach is to examine the variation in models. This approach examined the standard deviation of the growth of $\sigma(t)$ in the six MUP models for the uncontrolled run. This produced a much higher divergence, $0.32 \%$ per year from 2010 to 2100 .

For the uncertainty estimates, I chose a normal distribution using the results from the MUP differences. This produces an uncertainty of the annual growth of $\sigma(t)$ of $0.32 \%$ per year. This is higher than the time-series numbers, but seems to capture the errors. The major advantage is that it is conceptually the correct approach and contains structural elements. The major shortcoming is that it may underestimate the uncertainty as many ensembles do, but it seems less prone to clustering than other variables.

Carbon cycle. The carbon cycle has several parameters, but the most important one is the size of the intermediate reservoir (biosphere and upper level of the oceans). Changes in this have major impacts on atmospheric retention over the medium term (a century or more), while the other parameters affect primarily either the very short run or the very long run.

Since IAMs generally have primitive carbon cycles, I examined model comparisons of carbon cycles. A study by Friedlingstein et al. (2014) examined alternative predictions of 11 earth system models (ESMs) by calculating different emission-driven simulations of concentrations and temperature projections. These used the IPCC high emissions scenario (RCP 8.5). When forced by RCP $8.5 \mathrm{CO}_{2}$ emissions, models simulate a large spread in atmospheric $\mathrm{CO}_{2}$ concentrations, with 2100 concentrations ranging between 795 and 1145 parts per million volume (ppm). The standard deviation of the 2100 concentrations (conditional on the emissions trajectory) is $97 \mathrm{ppm}$. According to the study, differences in $\mathrm{CO}_{2}$ projections are mainly attributable to the response of the land carbon cycle, which suggests that the size of the intermediate reservoir is the uncertain parameter to adjust. While the ensemble standard deviation is not conceptually appropriate, as mentioned above, it is a useful benchmark for the purposes at hand. The final estimate uses a log-normal distribution for the carbon-cycle parameter.

\section{Damage function: core estimates}

The damage function was revised in the 2016 DICE version to reflect new findings. The 2013 version relied on estimates of monetized damages from the Tol (2009) survey, but it has 
since been determined that the Tol survey contained several numerical errors (see the Editorial Note 2015).

The current version of the DICE model continues to rely on existing damage studies. The method for estimating the damage function was the following: The new estimates started with a survey of damage estimates by Andrew Moffat and Nordhaus (2017). The underlying damage estimates were identified and collected. The survey turned up 27 studies which contained 36 useable damage estimates. For example, a recent version of the PAGE model estimated that the impact of a $4{ }^{\circ} \mathrm{C}$ warming would be to lower global output by $2.9 \%$. Using those 36 estimates as data points, we then fitted a number of different specifications to the estimates. The central specification was a one-parameter quadratic equation with a zero intercept and no linear term and was therefore a one-parameter function. (The weighted OLS version had the highest damage parameter; it was followed by the weighted median regression that is used; while the unweighted least squares and unweighted median regressions have the smallest estimated damage coefficients. "Largest" here means most negative.) Because the studies generally included only a subset of all potential impacts, we added an adjustment of 25 percent of quantified damages for omitted sectors and non-market and catastrophic damages, as explained in Nordhaus and Sztorc (2013). Including all factors, the damage equation in the model assumes that damages are $2.1 \%$ of global income at $3{ }^{\circ} \mathrm{C}$ warming and $8.5 \%$ of income at $6{ }^{\circ} \mathrm{C}$ warming. A full discussion of the estimates and statistical analysis are available in Nordhaus and Moffat (2017).

The parameter used in the model was an equation with a parameter of $0.227 \%$ loss in global income per ${ }^{\circ} \mathrm{C}$ squared with no linear term. This leads to a damage of $2.0 \%$ of income at 3 ${ }^{\circ} \mathrm{C}$, and $7.9 \%$ of global income at a global temperature rise of $6{ }^{\circ} \mathrm{C}$. This coefficient is slightly smaller than the parameter in the DICE-2013R model (which was $0.267 \%$ of income per ${ }^{\circ} \mathrm{C}$ squared). The change from the earlier estimate is due to corrections in the estimates from the Tol numbers, inclusion of several studies that had been omitted from that study, greater care in the selection of studies to be included, and the use of weighted regressions. Note also that the revised damage coefficient is the only change from the 2016R model used in Nordhaus (2017).

\section{Damage function: uncertainties}

The other key question is the uncertainty of the damage function to be used in the uncertainty analysis. One approach would be the standard error of the coefficient in the preferred equation above. The standard error from the preferred regression (including the $25 \%$ premium for omitted damages) is $0.0303 \%$ loss in global income per ${ }^{\circ} \mathrm{C}$ squared $\left(\mathrm{Y} /{ }^{\circ} \mathrm{C}^{2}\right)$ 
for a central coefficient of $0.236 \% \mathrm{Y} /{ }^{\circ} \mathrm{C}^{2}$. This corresponds to a t-statistic on the estimated coefficient of 7.8, so it is apparently extremely well-determined.

However, this estimate does not reflect specification uncertainty, uncertainty about the studies to be included, or study dependence. A broader approach to estimating the uncertainty can be taken by taking the calculated damages for all specifications of the damage function (both linear and quadratic, weighted and unweighted, and with different temperature thresholds) at a temperature increase of $6{ }^{\circ} \mathrm{C}$. This yields an uncertainty of $0.14 \% \mathrm{Y} /{ }^{\circ} \mathrm{C}^{2}$. Yet another estimate of uncertainty takes the standard deviation of the damage coefficients of the three models used by the Interagency Working Group, or IAWG (DICE, FUND, and PAGE); this yields a standard deviation of the damage coefficient of $0.15 \% \mathrm{Y} /{ }^{\circ} \mathrm{C}^{2}$.

Given the different approaches, I settled on a value for the uncertainty of the damage parameter which is one-half the mean value of the parameter. More precisely, the distribution is assumed to be normal, with a standard deviation of $0.118 \% \mathrm{Y} /{ }^{\circ} \mathrm{C}^{2}$. This reflects the great divergence today among different studies. ${ }^{\mathrm{i}}$

Table 1 shows the major assumptions of the model.

\section{Major results for DICE-2016R2}

\section{Central or best-guess (BG) estimates}

It will be useful to begin with results for the central values from the revised model. For this section, I use a best-guess approach, which has been the standard for the DICE model, most integrated assessment models, and virtually all earth-systems models. I use the term "best guess" to designate estimates in which the values of uncertain parameters and exogenous variables are set at their mean values.

Figures 2 through 4 show the projections of emissions, concentrations, and temperature increase for four scenarios with best-guess parameters. The four scenarios are the business as usual (BAU) or baseline ("Base"), which is the central version of no climate policy studied here; the cost-benefit economic optimum ("Opt"), which optimizes climate policy over the indefinite future; a path that limits temperature to $2 \frac{1}{2}{ }^{\circ} \mathrm{C}$ ( “ $\mathrm{T}<2.5^{\prime \prime}$ ); and a policy with an extremely low discount rate as advocated by the Stern Review ("Stern").

This study emphasizes the "baseline" or "no-policy" scenario. The baseline path takes current policy as of 2015, which I estimate to be the equivalent of a carbon price of $\$ 2$ per ton of $\mathrm{CO}_{2}$, and projects this price forward at $2 \%$ per year. Figure 2 shows the paths of emissions under the four scenarios. The baseline has rising emissions (although the path is flatter than most other IAMs). The two ambitious paths require zero emissions of $\mathrm{CO}_{2}$ by mid-century, 
which is an extremely sharp break in trend. Both have emissions reductions that are far sharper than are consistent with the policies of any major region. The optimal policy has a flat trajectory for the next half-century.

Figure 3 shows the $\mathrm{CO}_{2}$ concentrations paths for the four policies. The interesting feature is that the two ambitious paths only require stabilization at close to today's level of 400 $\mathrm{ppm}$. The low levels of concentrations are the result of zero-emissions trajectories in the near future, yet still have high $\mathrm{CO}_{2}$ concentrations because of the inertia in the carbon cycle.

Figure 4 shows the temperature trajectories of the scenarios. The Stern and limit scenario asymptote to $21^{1} /{ }^{\circ} \mathrm{C}$ by the end of the $21^{\text {st }}$ century. The other paths grow sharply, either because of no controls ("Base") or due to inertia even with the adoption of strong policies ("Opt"). Again, the difficulty of limiting the temperature increase to $2{ }^{\circ} \mathrm{C}$ comes because policies have been deferred for so many years, and because of the great inertia in the carbon cycle and the climate system.

A surprising difference found when comparing the current and earlier versions of the DICE model is that the optimal trajectory is now closer to the base than to the ambitious scenarios. This is due to a combination of factors, such as climate-system inertia and the high costs of the limiting scenarios.

Table 2 shows the overall economic impact of different policies for the best-guess parameters. The first column is the objective function, using first period consumption as the numeraire. This is then compared with the sum of abatement costs and damages. The last two columns show the difference of each policy from the base (no-policy) case. The net effects are in discounted trillions of US international dollars. The objective function is approximately the present value of consumption at a constant $4.4 \%$ per year discount rate (although the actual discount rate declines over time). As can be seen, the optimal case raises discounted world income by $\$ 30$ trillion, or a little less than $1 \%$ of discounted consumption. The other policies (Stern and temperature-limit) lower discounted world income because they front-load the abatement relative to the optimal case.

It should be noted that the optimal policy depends crucially on the assumed damage function. If the damage function shows higher costs, or has sharp curvature at or around $2{ }^{\circ} \mathrm{C}$, as is implicitly assumed in international policies that have a $2{ }^{\circ} \mathrm{C}$ target, then the revised optimal policy would have much higher abatement, and the temperature-limit and Stern policies would be much more economically attractive. However, current damage studies do not at present display either of these features (see Nordhaus and Moffat 2017).

Comparison with other studies

The results of the DICE BG approach can be compared with other models and studies. Figure 5 shows the projected industrial emissions of $\mathrm{CO}_{2}$ over the coming century for baseline 
or no-policy scenarios. DICE-2016R2 is at the low end of different projections after midcentury. The reason (as explained above) is that the projected rate of decarbonization is higher than in earlier versions or other models. The lower emissions trend is reflected in the 2016 DICE version but not in most other model projections, which are often from models constructed several years ago.

Figure 6 shows the projected temperature trajectories in five different approaches. The IAMs project a temperature increase in the range of 3.3 to $4.2^{\circ} \mathrm{C}$ by the year 2100 . The results for DICE-2016R2 are at the higher end of comparable studies. The DICE results are above those of the EMF-22 modeling exercise, as well as the central projections from the MUP project (Gillingham et al. 2015). The top line is the ensemble average from the Fifth Assessment Report of the IPCC (2013) for the RCP 8.5 scenario. However, the IPCC RCP 8.5 projection has a higher radiative forcing than the baseline DICE-2016R2 model. In summary, the DICE temperature projection is slightly lower than the last version, is higher than most other IAMs for a baseline scenario, and is consistent with (although a little lower) than the IPCC RCP 8.5 ensemble average.

\section{Social cost of carbon ${ }^{8}$}

A key finding from IAMs is the social cost of carbon, or SCC. This term designates the economic cost caused by an additional ton of $\mathrm{CO}_{2}$ emissions or its equivalent. More precisely, it is the change in the discounted value of economic welfare from an additional unit of $\mathrm{CO}_{2}-$ equivalent emissions. The SCC has become a central tool used in climate-change policy, particularly in the determination of regulatory policies that involve greenhouse-gas emissions. Estimates of the SCC are necessarily complex, because they involve the full range of impacts from emissions, through the carbon cycle and climate change, as well as including the economic damages from climate change. At present, there are few established integrated assessment models (IAMs) which are available for the estimation of the entire path of cause and effect and can therefore calculate an internally consistent SCC. The DICE model is one of the major IAMs used by scholars and governments for estimating the SCC.

Table 3 shows alternative estimates of the SCC. The central estimate from the BG approach is $\$ 30 / \mathrm{t} \mathrm{CO}_{2}$ for 2015. Other estimates show the SCC for temperature limits and for different discount rates. We can also compare these estimates with those of the US government made by the Interagency Working Group on Social Cost of Carbon (IAWG 2015). The IAWG's

\footnotetext{
${ }^{8}$ A full discussion is contained in National Research Council (2016) and Nordhaus (2014). The discussion in this section draws upon Nordhaus (2017).
} 
concept is conceptually comparable to the baseline in the first row of Table 3. Nordhaus (2017) shows that, at comparable discount rates, the DICE-2016R2 estimate would be roughly twice that of the IAWG. This difference can be explained by the IAWG's use of an earlier version of the DICE model, which was then blended with two other models, both of which had lower SCCs than the earlier DICE model.

\section{Uncertainties about climate change and policies}

\section{Results for baseline run}

This section presents the results of the uncertainty analysis. To reiterate the approach, we divided the PDFs for each uncertain variable into quintiles, and then took the expected value of the parameter in each quintile. Asymmetrical PDFs were transformed slightly to preserve the means and standard deviations. We then took a full enumeration of all $5^{5}=3125$ equally probable states of the world. Table A-2 in the Appendix shows the means, standard deviations, and quintile values for the uncertain variables.

Table 4 shows key statistics for major variables. There are three statistics for central values, and three for uncertainty. Look first at the estimates of the temperature increase for 2100 for the baseline in panel A. The best guess (BG) for DICE is $4.10{ }^{\circ} \mathrm{C}$, while the mean is higher at $4.22{ }^{\circ} \mathrm{C}$, and the median is lower at $4.08^{\circ} \mathrm{C}$. These suggest that the distribution is close to slightly skewed, and that the BG slightly underestimates the estimates with uncertainty.

Other variables display considerable asymmetry in the distributions. The SCC for 2015 has a mean of $\$ 34.5 / \mathrm{t} \mathrm{CO}_{2}$, whereas the $\mathrm{BG}$ is about $15 \%$ lower at $\$ 30.0 / \mathrm{t} \mathrm{CO}$. Most variables are similarly skewed. Note that output is hugely underestimated in the best-guess case because of the large variability of the growth rate. The question as to whether the BG is a reasonable approximation is important, because its use vastly simplifies analysis. The answer is sometimes yes, sometimes no. Appendix Table A-3 provides a tabulation of variables and the bias from using the best-guess approach. Note the major bias in output over the longer run, which results from the high degree of uncertainty of productivity.

Table 4 also shows three measures of uncertainty: the standard deviation, the interquartile range (IQR), and the coefficient of variation (CV). Perhaps the most useful of these is the CV. The interesting feature here is that the $\mathrm{CV}$ is relatively low for geophysical variables such as the 2100 temperature increase and carbon concentrations, but much higher for economic variables such as output, damages, and the SCC. The high uncertainty of economic variables comes about largely due to output uncertainty. The long lags in geophysical variables 
plus the lower uncertainty of geophysical parameters produces lower uncertainty in those variables.

We show box plots for several variables in the next figures. Figure 7A is temperature, 7B is $\mathrm{CO}_{2}$ concentrations, $7 \mathrm{C}$ is the damage ratio, and 7D is the social cost of carbon. Notably, even at the low fence or bar (which is approximately $1 / 2 \%$ of outcomes), there is substantial climate change.

\section{Brief note on uncertainty in optimal runs}

The present study is primarily about the results of uncertainty for a baseline scenario. The results for the optimal run are broadly parallel, with the central optimal result shown above, and the uncertainties largely similar. Panel B of Table 4 shows the basic outcomes. One interesting result is that the SCC for the uncertain and BG cases are much closer in the optimal than in the baseline case. This arises because policy can adapt to SOWs with higher damages, reducing the SCC in extreme SOWs. Appendix Tables A-4 and A-5 shows the details for the baseline and optimal runs with uncertainties, while Appendix Tables A-6 and A-7 show the averages for the baseline and optimal runs by period.

One other interesting run concerns the potential for limiting temperature in the uncertain runs. We have estimated the distribution of outcomes where abatement is at its maximum (30\% in the 2015 period, $70 \%$ in the 2020 period, and $100 \%$ after that). This is the outer limit of what would be feasible with maximum abatement, and is unrealistic given the policies of major countries. The probability that the temperature increase in 2100 would be less than $2{ }^{\circ} \mathrm{C}$ is about $40 \%$ for the maximum-effort case (see Appendix Table A-8 for the results on this run).

\section{Contributions of individual variables}

Table 5 shows the contribution of the different variables to the overall uncertainty. These are calculated in two ways. Panel A starts from zero uncertainty, and introduces each variable one at a time. Panel B starts from full uncertainty, and reduces the uncertainty one variable at a time.

The importance of different variables differs for the endogenous variable at hand. The most important uncertainty across the board is the growth rate of productivity, and this affects virtually every variable in an important way.

The impact of productivity growth is generally clear, but paradoxical at times. The major paradoxes arise because of the effect of productivity growth on the real interest rate. In the 
Ramsey-Koopmans-Cass model, the real interest rate (or discount rate) is endogenous. With the current parameters, a higher rate of productivity growth leads to a higher discount rate. This of course implies that SOWs with higher productivity growth have higher emissions, higher temperature increases, and higher damages. However, because the discount rate is higher, higher productivity growth instead leads to a lower social cost of carbon, and conversely. For example, if productivity growth is high, global temperature in 2100 is $5.3^{\circ} \mathrm{C}$, the 2100 discount rate is $2.7 \%$ per year and the 2015 SCC is $\$ 27 /$ tCO2. With low productivity growth, global temperature in 2100 is $3.3^{\circ} \mathrm{C}$, the 2100 discount rate is $1.6 \%$ per year and the 2015 SCC is $\$ 53 / \mathrm{tCO} 2$.

As a central way to view uncertainty, the most useful variable is the SCC. This is important because it indicates how stringent policy should be today, whereas many other variables relate more closely to the distant future. For the SCC, three variables are important. The most significant is the damage coefficient. The other two, roughly equally significant, are productivity growth and the equilibrium temperature sensitivity. The carbon cycle and the emissions intensity are relatively unimportant for uncertainty about the SCC. It may be surprising that the uncertainty about carbon intensity has little effect on many variables, particularly the SCC. This result arises because changes in carbon intensity affect marginal damages and marginal costs almost equally, so the two changes largely offset each other.

\section{Comparisons with other estimates}

There are several other estimates of uncertainty in IAMs. The most convenient comparison is with the estimates from the MUP project (Gillingham et al. 2015). The MUP project presented the results of the first comprehensive study of uncertainty in climate change using multiple integrated assessment models, examining model and parametric uncertainties for population, total factor productivity, and climate sensitivity. The study also estimated the PDFs of key output variables, including $\mathrm{CO}_{2}$ concentrations, temperature, damages, and the social cost of carbon (SCC). A key feature of the study was that the PDFs of the uncertain variables were standardized, while the models themselves (and the means of all driving variables) were left at the modelers' baselines.

Table 6 shows comparisons of means, standard deviations, and coefficients of variation for major variables between the current study and the MUP study. Note that the DICE model used in that study was DICE-2013R, whereas the model used here is DICE-2016R2. As noted above, there have been several important changes in the specifications between the two versions of the DICE model, so for DICE there are both methodological differences and model differences between this study and the MUP study. 
The most useful statistic to examine is the coefficient of variation (CV) in the bottom panel of Table 6. For the DICE model, the CVs are close but generally lower in the present study, the exception being the SCC. It is likely that the lower growth of emissions is responsible for the lower $\mathrm{CVs}$ for $\mathrm{CO}_{2}$ and temperature. The increased $\mathrm{CV}$ for the SCC is unexplained.

We can also examine the model differences in the same panel. The striking feature here is the large differences in CVs across models. The CVs differed by a factor of $1 \frac{1}{2}$ to almost 3 among the six models.

The key finding of the present and earlier studies is striking: The uncertainties of geophysical variables such as $\mathrm{CO}_{2}$ concentrations and temperature are relatively low, in the order of one-fifth of their best-guess values. On the other hand, the uncertainties of economic variables are much larger, with CVs around 70\% for emissions, damages, output, and the SCC.

\section{Timing of information and optimal climate policy}

Although the future is uncertain, we will eventually learn which path we are on whether damages are high or low, and whether temperature sensitivity is high or low. For the baseline path, with minimal climate policies, the timing of our learning is unimportant because it is assumed not to affect policy. However, for the optimal case, policy will depend upon the scenario, and it is necessary to consider what we know and when we know it.

The optimal policy described up to now assumes a "learn, then act," or LtA, structure of decisions. In other words, the analysis implicitly assumes that the uncertainties about the future are resolved at the beginning, and then climate policy is decided on a state-contingent basis. With high damages, carbon prices are high, and conversely. Of course, this approach is unrealistic since uncertainties are only gradually resolved over time. The alternative approach, "act, then learn," or AtL, provides a more realistic approach to decisions - one in which, for example, abatement or carbon prices are determined without knowledge of the damage function. For an early path breaking approach to a decision-theoretic approach in which the structure of learning is examined, see Manne and Richels (1992).

The AtL approach to decisions cannot be fully incorporated into the current DICE uncertainty structure in the GAMS framework, because in the full model it requires 3125 parallel states of the world, and is computationally infeasible without an alternative algorithmic approach. Alternative techniques using recursive methods have made substantial progress in studying decisions with slowly resolved uncertainties (see Lemoine and Rudik 2017), but they do not incorporate the full DICE-model structure.

A small test case examines the impact of learning that is delayed until 2050. For this analysis, I took the two extreme quintiles for each uncertain variable (so this involves $2^{5}=32$ 
states of the world, rather than 3125 in the full uncertainty model). I then estimated the optimal carbon prices, assuming an LtA approach similar to the approach used for the full model. For the AtL example, I assumed that the optimal carbon prices are not state-contingent (i.e., are the same in all SOW) through 2050, and then are state-contingent after 2050. So, this alternative approach assumes no learning until 2050 and then complete learning after 2050.

The results of this simplified example indicate that the policies are relatively insensitive to late learning, although there is substantial value of learning. The optimal carbon price in the AtL approach is about $6 \%$ higher than for that of the LtA ( $\$ 36 / \mathrm{tCO} 2$ rather than $\$ 34 / \mathrm{tCO} 2$ in 2015, see Appendix Table A-9). However, there is substantial value of early information, with the discounted value of consumption \$3.7 trillion higher when information is available in 2015 rather than in 2050. This example indicates that using the learn, then act approach to policy is reasonably accurate in the DICE model with uncertainty. However, if major structural changes are introduced (particularly sharp discontinuities), then this result would need to be revisited.

\section{Conclusion}

The present study presents an updated set of results on the prospects for climate change using a revised integrated assessment model, DICE-2016R2. It also develops a new and simplified method for determining the uncertainties associated with climate change, and the extent to which simplified best-guess (BG) techniques provide an accurate representation of the revised and more complex model with uncertainty.

The results pertain primarily to a world without climate policies, which is reasonably accurate for virtually the entire globe today. The results show rapidly rising $\mathrm{CO}_{2}$ concentrations, temperature changes, and damages. Moreover, when the major parametric uncertainties are included, there is virtually no chance that the rise in temperature will be less than the target $2{ }^{\circ} \mathrm{C}$ without more stringent and comprehensive climate change policies.

It is worth emphasizing one further point about the impact of uncertainty on policy. The future is highly uncertain for virtually all variables, particularly economic variables such as future output, damages, and the social cost of carbon. It might be tempting to conclude that nations should wait until the uncertainties are resolved, or at least until the fog has lifted a little. The present study finds the opposite result. To reiterate, by taking uncertainties into account, the strength of policy (as measured by the social cost of carbon or the optimal carbon tax) would increase, not decrease. 


\section{References}

Archer, David, et al. 2009. "Atmospheric lifetime of fossil fuel carbon dioxide," Annual Reviews Earth Planetary Science, 37:117-34

Christensen, Peter, Kenneth Gillingham, and William Nordhaus. 2016. “Uncertainty in forecasts of long-run productivity growth," manuscript in preparation.

Clarke, Leon, et al. 2009. "International climate policy architectures: Overview of the EMF 22 international scenarios.” Energy Economics, 31: S64-S81.

Editorial Note. 2015. "Editorial Note: Correction to Richard S. Tol's 'the economic effects of climate change'," Journal of Economic Perspectives, vol. 29, no. 1, Winter, 217-20.

Friedlingstein, Pierre, Malte Meinshausen, Vivek K. Arora, Chris D. Jones, Alessandro Anav, Spencer K. Liddicoat, and Reto Knutti. 2014. "Uncertainties in CMIP5 Climate Projections due to Carbon Cycle Feedbacks," Journal of Climate, 27: 511-526.

Gillingham, Kenneth, William D. Nordhaus, David Anthoff, Geoffrey Blanford, Valentina Bosetti, Peter Christensen, Haewon McJeon, John Reilly, and Paul Sztorc. 2015. "Modeling uncertainty in climate change: a multi-model comparison." No. w21637. National Bureau of Economic Research.

Gollier, Christian. 2013. Pricing the Planet's Future: The Economics of Discounting in an Uncertain World. Princeton University Press.

IAWG. 2015. Interagency Working Group on Social Cost of Carbon, United States Government, Response to Comments: Social Cost of Carbon for Regulatory Impact Analysis Under Executive Order 12866, July, available at https://www.whitehouse.gov/sites/default/files/omb/inforeg/scc-response-to-commentsfinal-july-2015.pdf.

IPCC Fifth Assessment Report, Science. 2013. Intergovernmental Panel on Climate Change, Climate Change 2013: The Physical Science Basis, Contribution of Working Group I to the Fifth 
Assessment Report of the IPCC, available online at http://www.ipcc.ch/report/ar5/wg1/\#.Ukn99hCBm71.

Lemoine, Derek and Ivan Rudik. 2017. "Managing Climate Change under uncertainty: Recursive integrated assessment at an inflection point," Annual Review of Resource Economics 9.

Manne, Alan .S. and Richard G. Richels. 1992. Buying greenhouse insurance: the economic costs of carbon dioxide emission limits. MIT press.

Mizon, Grayham E. and David F. Hendry. 1980. "An Empirical Application and Monte Carlo Analysis of Tests of Dynamic Specification," The Review of Economic Studies, Vol. 47, No. 1, Econometrics Issue, 21-45.Müller, U. and M. Watson. 2016. "Measuring Uncertainty about longrun predictions," Review of Economic Studies, 83: 1711-1740.

National Research Council. 2017. Valuing Climate Damages: Updating Estimation of the Social Cost of Carbon Dioxide, Report of the Committee on Assessing Approaches to Updating the Social Cost of Carbon, National Academy Press: Washington, D.C.

Nordhaus, William D. 1992. "An optimal transition path for controlling greenhouse gases," Science, 258, November 20: 1315-1319.

Nordhaus, William D. 1994. Managing the Global Commons: The Economics of Climate Change, MIT Press, Cambridge, MA, USA.

Nordhaus, W. 2008. A Question of Balance: Weighing the Options on Global Warming Policies. New Haven, CT: Yale University Press.

Nordhaus, William. 2014. "Estimates of the social cost of carbon: concepts and results from the DICE-2013R model and alternative approaches." Journal of the Association of Environmental and Resource Economists, 1, no. 1/2: 273-312.

Nordhaus, William. 2015. "Climate clubs: Overcoming free-riding in international climate policy." American Economic Review, 105.4: 1339-70

Nordhaus, William. 2017. “The social cost of carbon: Updated estimates.” Proceedings of the U. S. National Academy of Sciences, vol. 114 no. 7, 1518-1523. 
Nordhaus, William. 2017a. "Evolution of Assessments of the Economics of Global Warming: Changes in the DICE model, 1992-2017" (No. w23319). National Bureau of Economic Research and Cowles Foundation Discussion Paper.

Nordhaus, William and Andrew Moffat. 2017. "A Survey of Global Impacts of Climate Change: Replication, Survey Methods, and a Statistical Analysis." National Bureau of Economic Research Working Paper and Cowles Foundation Discussion Paper.

Nordhaus, William and Paul Sztorc. 2013. DICE 2013R: Introduction and User's Manual, October 2013, available at http://www.econ.yale.edu/ nordhaus/homepage/ documents/DICE Manual 100413r1.pdf.

Olsen, R., R. Sriver, M. Goes, N. Urban, D. Matthews, M. Haran, and K. Keller. 2012. "A Climate Sensitivity Estimate Using Bayesian Fusion of Instrumental Observations and an Earth System Model." Geophysical Research Letters 117(D04103): 1-11.

Paris Agreement. 2016. United Nations Framework Convention on Climate Change, The Paris Agreement, available at http://unfccc.int/paris agreement/items/9485.php.

Stern Review. 2007. The Economics of Climate Change: The Stern Review, Cambridge University Press: Cambridge, UK.

Tol, R.S.J. 2009. "The Economic Impact of Climate Change," Journal of Economic Perspectives, 23 (2): 29-51. 


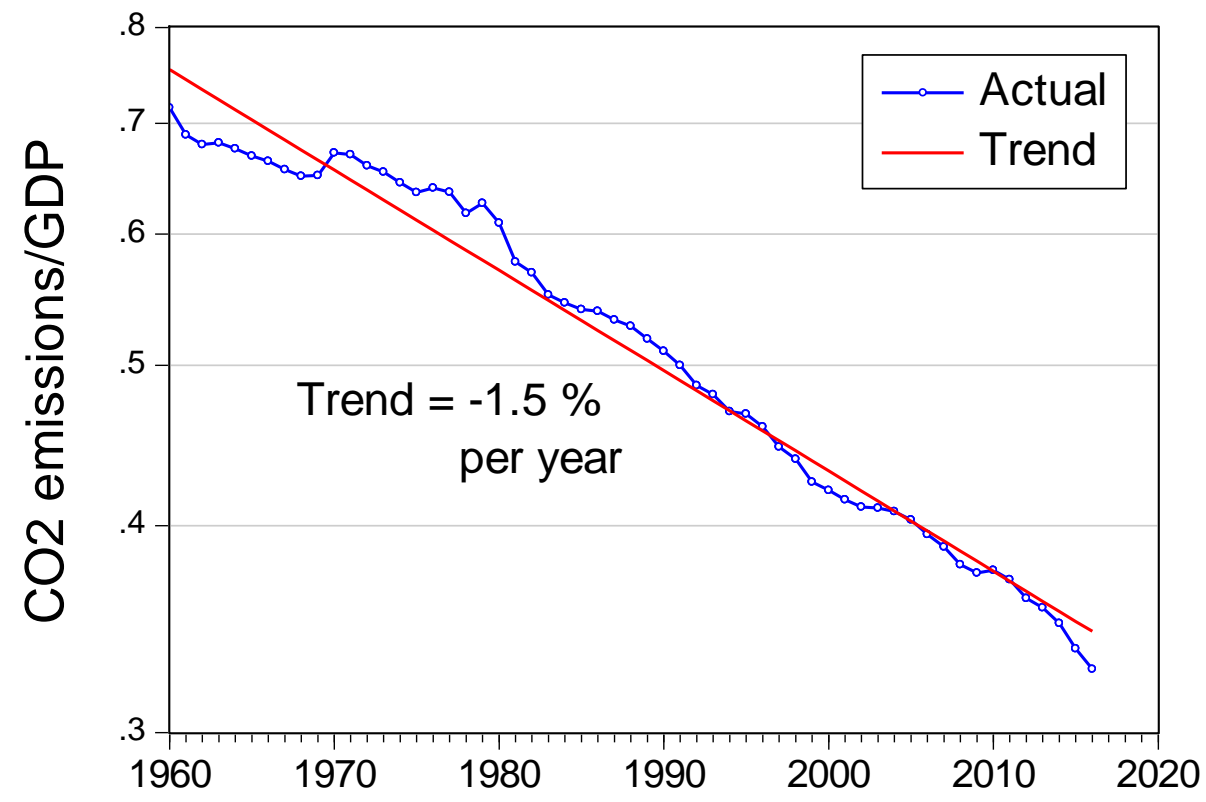

Figure 1. Global trend and actual history for $\mathrm{CO}_{2} / \mathrm{GDP}$ ratio 


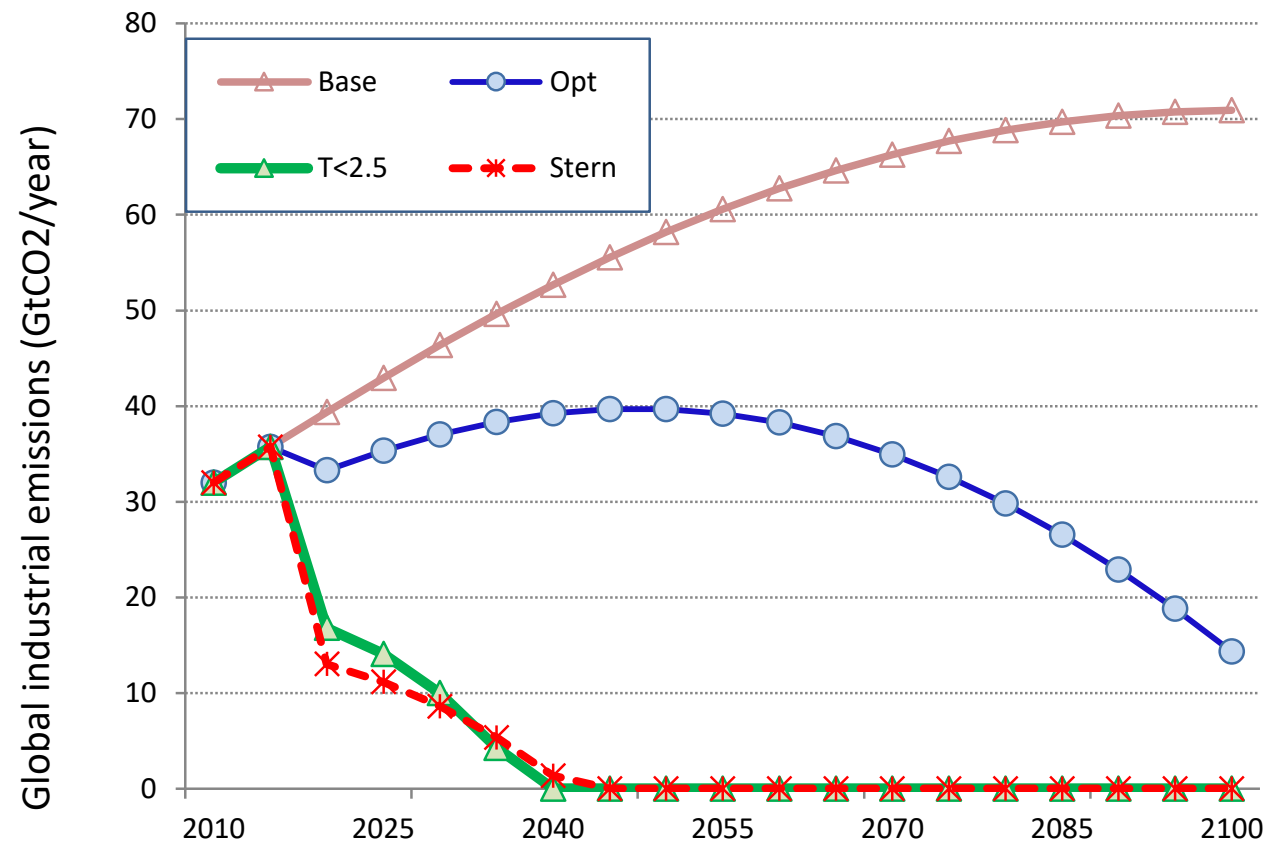

Figure 2. Actual and projected emissions of $\mathrm{CO}_{2}$ in different scenarios The two most ambitious scenarios require zero emissions by mid-century. ${ }^{\mathrm{i}}$ 


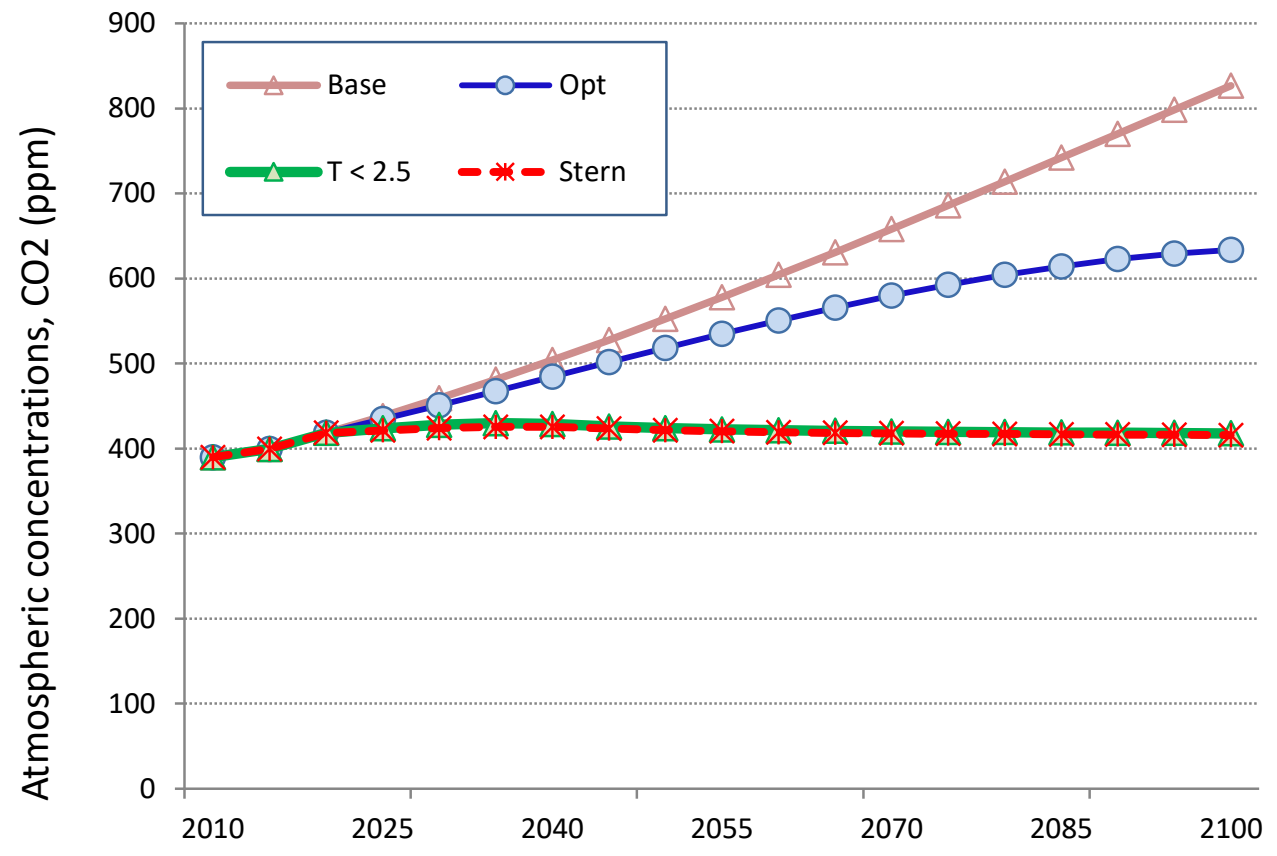

Figure 3.Concentrations of $\mathrm{CO}_{2}$ in different scenarios

The two most ambitious scenarios require concentrations emissions close to current levels. 


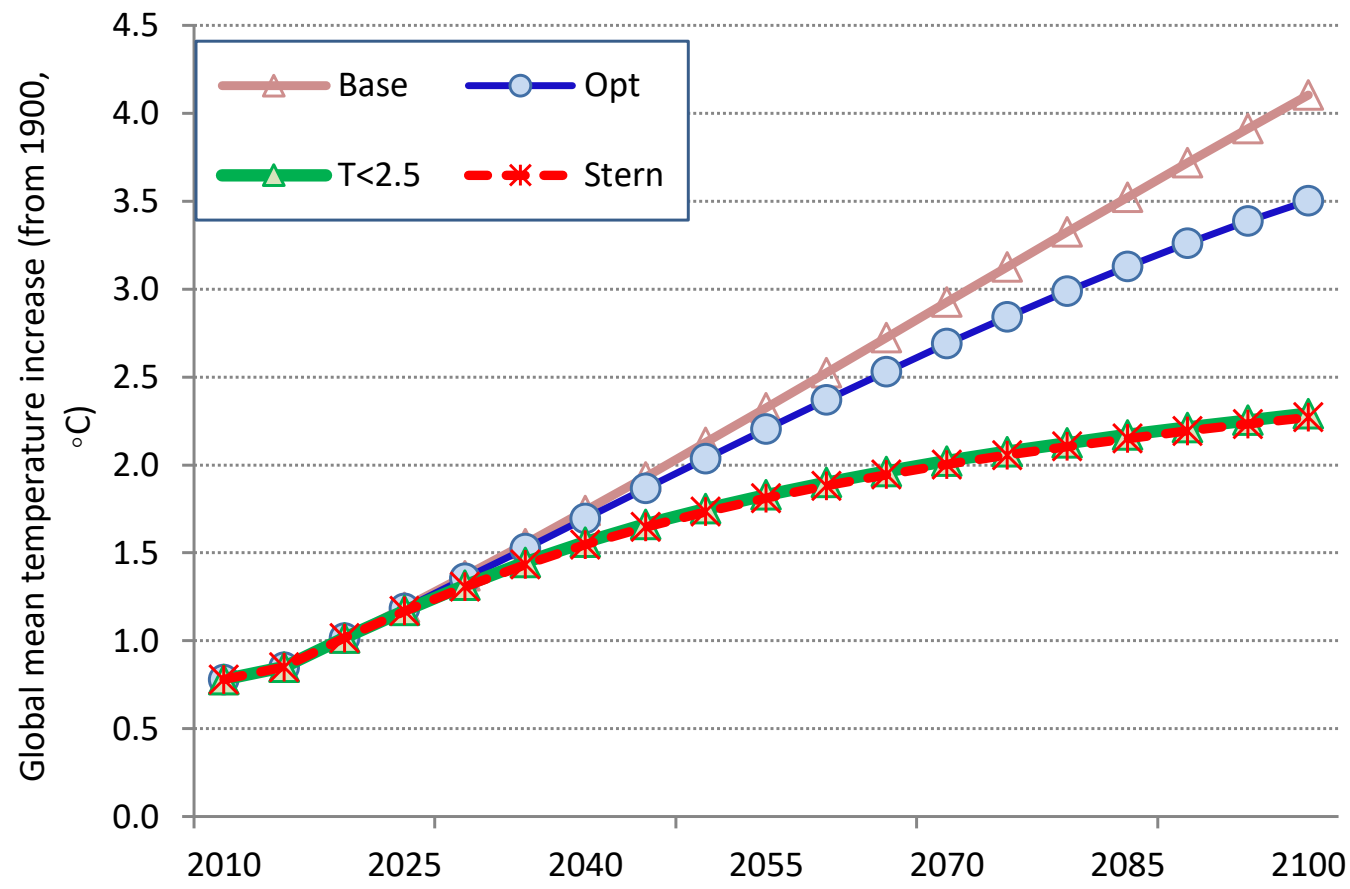

Figure 4. Temperature change in different scenarios

The most ambitious scenarios cannot limit temperature to $2 \frac{1}{2}{ }^{\circ} \mathrm{C}$, and the cost-benefit optimum with standard parameters has sharply rising temperatures..$^{i i i}$

\{?? I see "From 1900" here and for Figure 6, but the data is plotted from approximately 2010. ??\} 


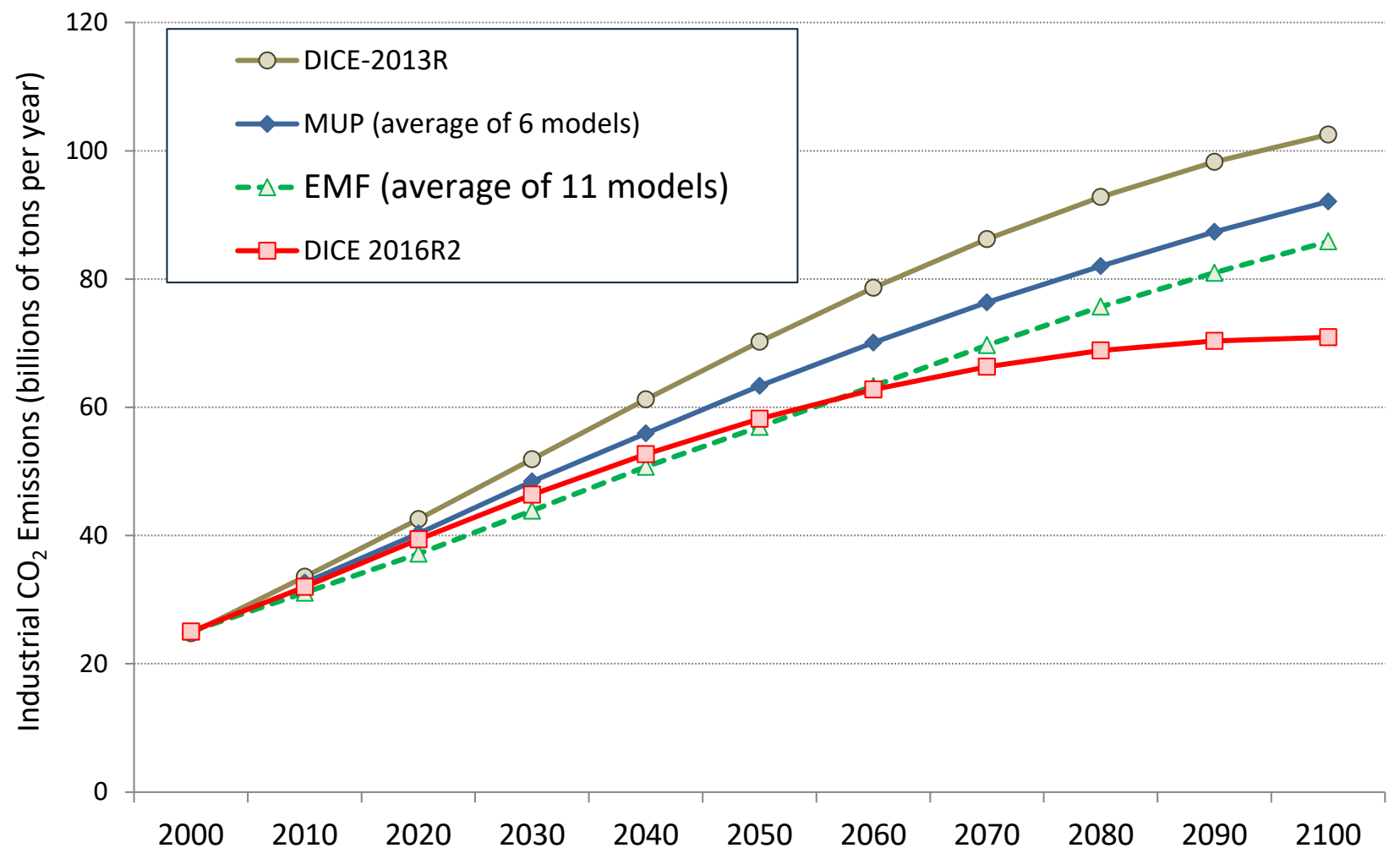

Figure 5. Projected industrial $\mathrm{CO}_{2}$ emissions in baseline scenario, alternative models The figure compares the projections of the most recent DICE models and two model comparison exercises. The estimates from the MUP project are from Gillingham et al. (2015), while the EMF-22 estimates are from Clarke et al. (2009). 


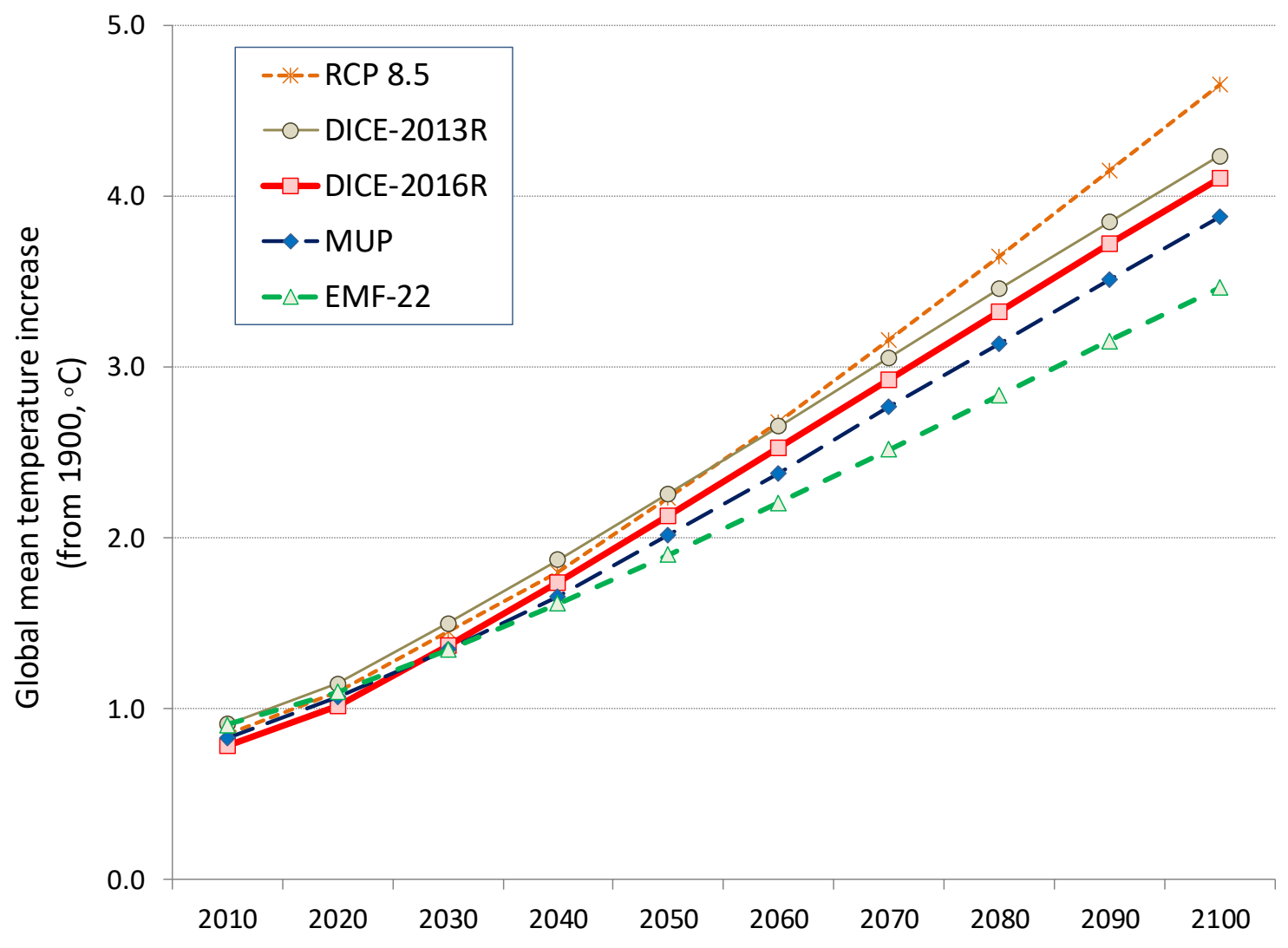

Figure 6. Global mean temperature increase as projected by IPCC scenarios and integrated assessment economic models

The figure compares the projections of the most recent DICE models, the IPCC high scenario (RCP 8.5), and two model comparison exercises. 

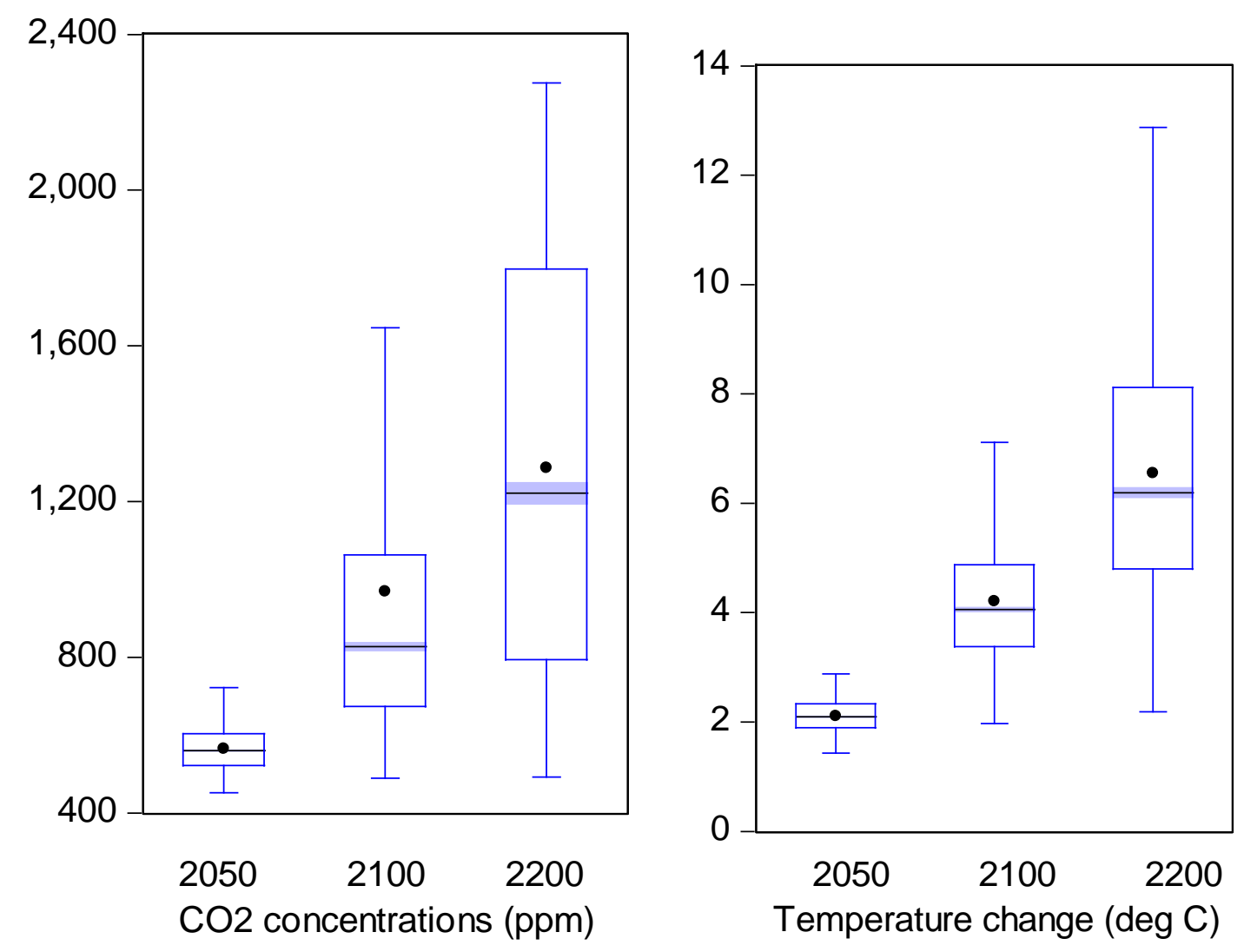

Figure 7A. Boxplots for major uncertain variables.

The interpretation is that the line in the middle of the box is the median, while the shaded region around the line is the standard error of the median. The dot is the mean. The box shows the interquartile range, IQR (= Q3-Q1), while the fences (upper and lower bars) are at Q1 1.5 $\times$ IQR and Q3 + 1.5 $\times$ IQR. For a normal distribution, the fences contain $99.2 \%$ of the distribution. ${ }^{\text {iv }}$ 

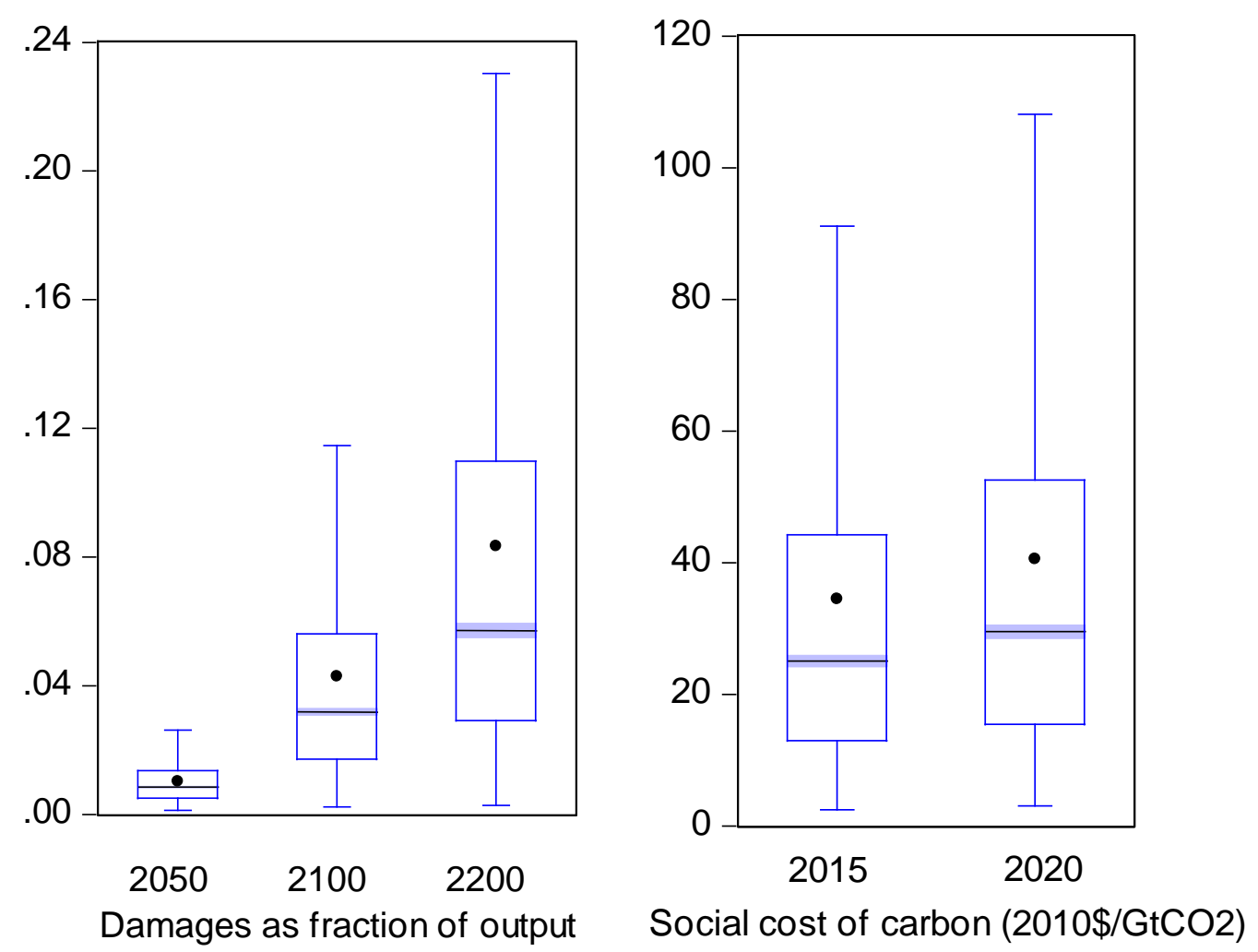

Figure 7B. Boxplots for major uncertain variables.

For interpretation, see Figure 7A. 
Economic variables

Output growth

Population growth

Output per capita growth

Decarbonization rate

Real interest rate

Price of backstop technology

\section{Geophysical variables}

Equilibrium temperature sensitivity $\left({ }^{\circ} \mathrm{C}\right)$

Transient temperature sensitivity $\left({ }^{\circ} \mathrm{C}\right)$

Average carbon retention rate (\%) $\underline{2015-2050} \quad \underline{2050-2100}$

$2.97 \%$

$1.92 \%$

$0.80 \% \quad 0.25 \%$

$2.15 \% \quad 1.67 \%$

$-1.49 \% \quad-1.42 \%$

$\underline{2015} \quad \underline{2100}$

$5.1 \% \quad 3.6 \%$

$550 \quad 357$

Parameter value

1.7

67

\section{Notes on variables}

Output is world output in constant US international \$.

Decarbonization rate is base $\mathrm{CO}_{2}$ emissions per real $\$$ output.

Real interest rate is the rate of return on capital (\% per year).

Price of backstop technology is the price at which $\mathrm{CO} 2$ emissions are zero.

Equilibrium temperature sensitivity is the equilibrium rise in global mean surface temperature for a doubling of atmospheric $\mathrm{CO} 2$ concentrations.

Transient temperature sensitivity is the rise in global mean surface temperature for a doubling of atmospheric $\mathrm{CO} 2$ concentrations after 70 years.

Average carbon retention rate is the percentage of cumulative $\mathrm{CO} 2$ emissions that remains in the atmosphere for emissions between 2010 and 2100 .

Table 1. Key assumptions for DICE-2016R2 model for best-guess case ${ }^{\mathrm{v}}$ 


\begin{tabular}{|c|c|c|c|c|c|c|}
\hline \multirow[b]{2}{*}{ Scenario } & \multirow[b]{2}{*}{ Objective } & \multirow[b]{2}{*}{ Damages } & \multirow[b]{2}{*}{$\begin{array}{c}\text { Abatement } \\
\text { cost }\end{array}$} & \multirow[b]{2}{*}{$\begin{array}{l}\text { Damages } \\
\text { plus } \\
\text { abatement }\end{array}$} & \multicolumn{2}{|c|}{ Difference from base } \\
\hline & & & & & Objective & $\begin{array}{l}\text { Damages plus } \\
\text { abatement }\end{array}$ \\
\hline Base or business as usual & $4,491.07$ & 134.2 & 0.4 & 134.6 & 0.0 & 0.0 \\
\hline Optimal controls & $4,520.56$ & 84.6 & 20.1 & 104.7 & 29.5 & 29.9 \\
\hline 2.5 degree maximum & & & & & & \\
\hline Maximum (b) & $4,441.32$ & 43.1 & 134.6 & 177.8 & -49.7 & -43.2 \\
\hline Max for 100 years (b) & $4,456.81$ & 45.7 & 117.6 & 163.3 & -34.3 & -28.8 \\
\hline Stern Review abatement & & 46.2 & 155.7 & 201.9 & na & -67.3 \\
\hline
\end{tabular}

All figures are trillions of US international \$ in 2010 prices.

Table 2. Abatement, Damages, and Net Impacts of Different Policy Scenarios, Best-Guess Parameters. ${ }^{\text {i }}$

The estimates in the last two columns represent the present value of the difference in the scenario from the base or business as usual case. The present values for damages and abatement use the discount factors from the base case. For this reason, the differences from base in the last two columns differ slightly for alternative scenarios. Note that the objective function for the Stern case is not applicable (na) because the preference parameters in that case differ from the other cases. 


\begin{tabular}{|l|rrrrr|}
\hline Scenario & $\underline{2015}$ & $\underline{2020}$ & $\underline{2025}$ & $\underline{2030}$ & $\underline{2050}$ \\
\hline Base parameters & & & & & \\
Baseline (a) & 30.0 & 35.7 & 42.3 & 49.5 & 98.3 \\
Optimal controls (b) & 29.5 & 35.3 & 41.8 & 49.2 & 99.6 \\
2.5 degree maximum & & & & & \\
Maximum (b) & 184.1 & 229.0 & 284.0 & 351.0 & $1,008.4$ \\
Max for 50 years (b) & 147.2 & 183.2 & 227.2 & 280.4 & 773.5 \\
& & & & & \\
Stern Review discounting & & & & & \\
Uncalibrated (b) & 256.5 & 299.6 & 340.7 & 381.7 & 615.6 \\
Alternative discount rates (a) & & & & & \\
2.5\% & 111.1 & 133.4 & 148.7 & 162.3 & 242.6 \\
$3 \%$ & 71.6 & 85.3 & 94.4 & 104.0 & 161.7 \\
$4 \%$ & 34.0 & 39.6 & 44.5 & 49.8 & 82.1 \\
$5 \%$ & 18.9 & 21.7 & 24.8 & 28.1 & 48.4 \\
\hline
\end{tabular}

Table 3. Global social cost of carbon by different assumptions for best-guess parameters The social cost of carbon is measured in 2010 international US dollars. The years at the top refer to the date at which emissions take place. Therefore, $\$ 30.0$ is the cost of emissions in 2015 in terms of consumption in 2015. (a) Calculation along the reference path with current policy. In the baseline calculation, welfare is maximized as in (1) but when damages are set to zero for the optimization but included in the ex post calculation. (b) Calculation along the optimized emissions path. Note that for the temperature ceilings, the damages are included. By putting a cap on temperature, this implicitly assumes that the damages are infinite beyond that limit. ${ }^{\text {vii }}$ 
A. Results for Baseline Scenario ${ }^{\text {viii }}$

\begin{tabular}{|l|r|r|r|r|r|r|}
\hline Variable & Mean & $\begin{array}{r}\text { DICE best } \\
\text { guess }\end{array}$ & $50 \%$ ile & St Dev & IQ range & Coef of Var \\
\hline SCC, 2015 & 34.5 & 30.0 & 25.2 & 32.5 & 39.3 & 0.94 \\
Temperature, 2100 ( $\left.{ }^{\circ} \mathrm{C}\right)$ & 4.22 & 4.10 & 4.08 & 1.12 & 2.01 & 0.22 \\
Carbon concentrations, 2100 (ppm) & 969.6 & 826.6 & 829.8 & 413.3 & 488 & 0.12 \\
World output, 2100 (trillions 2010 \$) & 1,433 & 759 & 766 & 1,660 & 1,056 & 0.67 \\
Emissions 2100 & 109.4 & 70.9 & 71.1 & 105.2 & 114.5 & 0.63 \\
Damages, 2100 (\% output) & $4.3 \%$ & $3.8 \%$ & $3.2 \%$ & $3.7 \%$ & $4.9 \%$ & 0.67 \\
Real interest rate, 2100 (\%/yr) & $3.6 \%$ & $3.6 \%$ & $3.6 \%$ & $1.6 \%$ & $2.2 \%$ & 0.33 \\
Objective (trillions, 2010\$) & 3,838 & 4,491 & 4,513 & 2,978 & 6,069 & 0.62 \\
\hline
\end{tabular}

B. Results for Optimal Scenario ${ }^{\text {ix }}$

\begin{tabular}{|l|r|r|r|r|r|r|}
\hline Variable & Mean & $\begin{array}{r}\text { DICE best } \\
\text { guess }\end{array}$ & $50 \%$ ile & St Dev & IQ range & Coef of Var \\
\hline SCC, 2015 & 32.5 & 29.6 & 24.3 & 28.6 & 37.0 & 0.88 \\
Temperature, $2100\left({ }^{\circ} \mathrm{C}\right)$ & 3.50 & 3.50 & 3.43 & 0.75 & 2.01 & 0.22 \\
Carbon concentrations, 2100 (ppm) & 669.8 & 633.1 & 624.8 & 188.5 & 488 & 0.12 \\
World output, 2100 (trillions 2010 \$) & 1,496 & 766 & 772 & 1,753 & 1,056 & 0.67 \\
Emissions 2100 & 20.6 & 14.1 & 11.1 & 34.1 & 114.5 & 0.63 \\
Damages, 2100 (\% output) & $2.6 \%$ & $2.8 \%$ & $2.4 \%$ & $1.4 \%$ & $4.9 \%$ & 0.67 \\
Real interest rate, 2100 (\%/yr) & $3.7 \%$ & $3.6 \%$ & $3.7 \%$ & $1.7 \%$ & $2.2 \%$ & 0.33 \\
Objective (trillions, 2010\$) & 3,873 & 4,519 & 4,533 & 2,982 & 6,069 & 0.62 \\
\hline
\end{tabular}

Table 4. Statistics for major variables

The table shows statistics for major variables from the discretized uncertainty analysis for baseline and optimal scenarios. For a more complete tabulation, see appendix tables. "DICE best guess" sets the uncertain parameters at their expected value. 
A. From zero uncertainty

\begin{tabular}{|l|r|r|r|r|r|r|r|r|}
\hline $\begin{array}{l}\text { Fraction (if only } \\
\text { uncertainty) }\end{array}$ & $\mathrm{SCC}, 2015$ & $\begin{array}{r}\text { Temp, } \\
2100\end{array}$ & $\begin{array}{c}\text { CO2 conc, } \\
2100\end{array}$ & $\begin{array}{r}\text { Output, } \\
2100\end{array}$ & $\begin{array}{c}\text { Emissions, } \\
2100\end{array}$ & $\begin{array}{c}\text { Damage } \\
\text { fraction, } \\
2100\end{array}$ & $\begin{array}{c}\text { Interest } \\
\text { rate, 2100 }\end{array}$ & $\begin{array}{c}\text { Global } \\
\text { income } \\
\text { (PV) }\end{array}$ \\
\hline Productivity & $38 \%$ & $60 \%$ & $61 \%$ & $37 \%$ & $57 \%$ & $37 \%$ & $65 \%$ & $91 \%$ \\
Damage & $54 \%$ & $1 \%$ & $1 \%$ & $2 \%$ & $1 \%$ & $57 \%$ & $6 \%$ & $2 \%$ \\
Equil. Temp. Sens. & $35 \%$ & $61 \%$ & $0 \%$ & $1 \%$ & $1 \%$ & $35 \%$ & $4 \%$ & $2 \%$ \\
Carbon cycle & $6 \%$ & $23 \%$ & $14 \%$ & $0 \%$ & $0 \%$ & $14 \%$ & $1 \%$ & $1 \%$ \\
Emissions intensity & $0 \%$ & $17 \%$ & $17 \%$ & $0 \%$ & $19 \%$ & $10 \%$ & $2 \%$ & $1 \%$ \\
\hline All & $100 \%$ & $100 \%$ & $100 \%$ & $100 \%$ & $100 \%$ & $100 \%$ & $100 \%$ & $100 \%$ \\
\hline
\end{tabular}

B. From full uncertainty

\begin{tabular}{|l|r|r|r|r|r|r|r|r|}
\hline $\begin{array}{l}\text { Fraction (if only } \\
\text { uncertainty reduced) }\end{array}$ & SCC, 2015 & $\begin{array}{c}\text { Temp, } \\
2100\end{array}$ & $\begin{array}{c}\text { CO2 conc, } \\
2100\end{array}$ & $\begin{array}{r}\text { Output, } \\
2100\end{array}$ & $\begin{array}{r}\text { Emissions, } \\
2100\end{array}$ & $\begin{array}{r}\text { Damage } \\
\text { fraction, } \\
2100\end{array}$ & $\begin{array}{c}\text { Interest } \\
\text { rate, } 2100\end{array}$ & $\begin{array}{c}\text { Global } \\
\text { income } \\
\text { (PV) }\end{array}$ \\
\hline Productivity & $37 \%$ & $39 \%$ & $80 \%$ & $98 \%$ & $83 \%$ & $35 \%$ & $93 \%$ & $97 \%$ \\
Damage & $51 \%$ & $20 \%$ & $43 \%$ & $64 \%$ & $50 \%$ & $64 \%$ & $37 \%$ & $19 \%$ \\
Equil. Temp. Sens. & $35 \%$ & $42 \%$ & $43 \%$ & $65 \%$ & $50 \%$ & $32 \%$ & $37 \%$ & $19 \%$ \\
Carbon cycle & $22 \%$ & $23 \%$ & $45 \%$ & $65 \%$ & $50 \%$ & $26 \%$ & $37 \%$ & $19 \%$ \\
Emissions intensity & $16 \%$ & $21 \%$ & $44 \%$ & $67 \%$ & $50 \%$ & $24 \%$ & $41 \%$ & $18 \%$ \\
\hline
\end{tabular}

Table 5. Impact on uncertainty of individual uncertain variables

Table shows the contribution (as fraction of total uncertainty) for each uncertainty. Panel A starts from zero uncertainty and then introduces the impact of adding the uncertainty about a single variable from a base of no uncertainty (one at a time). Panel B shows the reduction in uncertainty starting from full (five-variable) uncertainty and eliminating the uncertainty about a single variable (one at a time). ${ }^{x}$ 


\begin{tabular}{|c|c|c|c|c|c|c|c|c|}
\hline \multirow[b]{3}{*}{ Variable } & \multicolumn{8}{|c|}{ Mean of variable } \\
\hline & \multirow{2}{*}{$\begin{array}{l}\text { This study } \\
\text { DICE-2016 }\end{array}$} & & & & & & & \\
\hline & & DICE-2013 & FUND & GCAM & IGSM & MERGE & WITCH & Average \\
\hline SCC, 2015 & 34.49 & 21.87 & 2.75 & na & na & na & 15.47 & 13.36 \\
\hline Carbon concentrations, 2100 (ppm) & 969.6 & 939.3 & 906.9 & 860.7 & 810.8 & 998.6 & 854.1 & 895.1 \\
\hline Emissions 2100 & 109.4 & 127.7 & 142.7 & 90.2 & 71.3 & 168.7 & 90.5 & 115.2 \\
\hline
\end{tabular}

\begin{tabular}{|c|c|c|c|c|c|c|c|c|}
\hline \multirow{2}{*}{ Variable } & \multicolumn{8}{|c|}{ Standard deviation of variable } \\
\hline & This study & & & & & & & \\
\hline SCC, 2015 & 32.55 & 15.25 & 2.17 & na & na & na & 4.46 & 7.30 \\
\hline Carbon concentrations, 2100 (ppm) & 413.3 & 318.3 & 353.8 & 222.1 & 130.9 & 325.1 & 134.2 & 247.4 \\
\hline Emissions 2100 & 105.2 & 92.5 & 145.8 & 52.7 & 29.8 & 130.0 & 34.6 & 80.9 \\
\hline
\end{tabular}

\begin{tabular}{|c|c|c|c|c|c|c|c|c|}
\hline \multirow{2}{*}{ Variable } & \multicolumn{8}{|c|}{ Coefficient of variation of variable } \\
\hline & This study & & & & & & & \\
\hline SCC, 2015 & 0.94 & 0.70 & 0.79 & na & na & na & 0.29 & 0.55 \\
\hline Carbon concentrations, 2100 (ppm) & 0.43 & 0.34 & 0.39 & 0.26 & 0.16 & 0.33 & 0.16 & 0.28 \\
\hline Emissions 2100 & 0.96 & 0.72 & 1.02 & 0.58 & 0.42 & 0.77 & 0.38 & 0.70 \\
\hline
\end{tabular}

Table 6. Comparative statistics from current study and other models ${ }^{\mathrm{xi}}$ 


\section{Appendix.}

\section{A. Response Surface Method to Calculate Distributions}

The study uses an approach with exact discretized distributions of the five uncertain variables. We test the accuracy of the approach using a response surface method. This approach is used extensively for the analysis of complex engineering and biochemical problems (for example, the strength of Roman cement) and was developed for this purpose in Gillingham et al. (2015). The basic idea is to fit a high-order polynomial function of the uncertain variables to the 3125 grid points using a response surface function (RSF), and then estimate the distribution of the output variables using a Monte Carlo with a large number of draws $(\mathrm{N}=1,000,000)$.

Table A-1 compares the results of the two approaches. The first four columns show estimated means and standard deviations for major variables with the discretized version used in the text ("Discretized") and in the RSF approach ("Monte Carlo"). The fifth and sixth columns show the ratios of the means and standard deviations for the two approaches. All estimates using the discretized distributions are seen to be highly reliable using this technique. The means are essentially identical. The standard deviations differ by at most 3\%. The SRF tends to have a slightly lower standard deviation.

\begin{tabular}{|l|r|r|r|r|r|r|}
\hline \multirow{2}{*}{ Outcome variable } & Monte Carlo & Monte Carlo & Discretized & Discretized & $\begin{array}{c}\text { Ratio } \\
\text { (MC/D) }\end{array}$ & $\begin{array}{c}\text { Ratio } \\
\text { (MC/D) }\end{array}$ \\
\cline { 2 - 7 } & \multicolumn{1}{|c|}{ Mean } & \multicolumn{1}{c|}{ St Dev } & \multicolumn{1}{c|}{ Mean } & \multicolumn{1}{c|}{ St Dev } & Mean & \multicolumn{1}{c|}{ St Dev } \\
\hline Damage fraction 2100 & 0.0430 & 0.0361 & 0.0430 & 0.0364 & 1.000 & 0.994 \\
Output 2100 & $1,432.5$ & $1,661.5$ & $1,433.0$ & $1,651.6$ & 1.000 & 1.006 \\
Carbon conc 2100 & $2,064.7$ & 866.2 & $2,065.3$ & 879.1 & 1.000 & 0.985 \\
Emissions 2100 & 109.4 & 103.3 & 109.4 & 104.7 & 1.000 & 0.986 \\
Temperature 2100 & 4.217 & 1.083 & 4.216 & 1.117 & 1.000 & 0.970 \\
SCC 2015 & 34.525 & 32.209 & 34.489 & 32.185 & 1.001 & 1.001 \\
\hline
\end{tabular}

Table A-1. Comparison of statistics with discretized quintile distribution and response surface methodxii 


\section{B. Supplementary Tables}

\begin{tabular}{|l|r|r|r|r|r|r|r|}
\hline Uncertain parameter & Average & $\begin{array}{c}\text { Standard } \\
\text { deviation }\end{array}$ & Q1 & Q2 & Q3 & Q4 & Q5 \\
\hline $\begin{array}{l}\text { Damage coefficient } \\
\left(\mathrm{Y} /{ }^{\circ} \mathrm{C}\right)^{2}\end{array}$ & 0.0023 & 0.0014 & 0.0007 & 0.0017 & 0.0023 & 0.0029 & 0.0039 \\
$\begin{array}{l}\text { Productivity growth } \\
\text { (\%/year) }\end{array}$ & $1.52 \%$ & $1.12 \%$ & $-0.05 \%$ & $0.92 \%$ & $1.52 \%$ & $2.12 \%$ & $3.09 \%$ \\
$\begin{array}{l}\text { Equilibrium } \\
\text { temperature sensitivity } \\
\left({ }^{\circ} \mathrm{C} / 2 \times C O 2\right)\end{array}$ & 3.10 & 0.84 & 2.10 & 2.63 & 3.10 & 3.48 & \\
$\begin{array}{l}\text { Rate of decarbonization } \\
\text { (\% per year) }\end{array}$ & $-1.52 \%$ & $0.32 \%$ & $-1.97 \%$ & $-1.69 \%$ & $-1.52 \%$ & $-1.35 \%$ & $-1.07 \%$ \\
$\begin{array}{l}\text { Carbon in intermediate } \\
\text { reservoir (GtC) }\end{array}$ & 360.0 & 97.0 & 241.7 & 302.2 & 360.0 & 400.6 & 507.7 \\
\hline
\end{tabular}

Table A-2. Means, standard deviations, and quintile values of uncertain variables ${ }^{x i i}$ 


\begin{tabular}{|c|c|c|c|c|}
\hline Variable & Mean & $50 \%$ ile & $\begin{array}{c}\text { DICE best } \\
\text { guess }\end{array}$ & $\begin{array}{c}\text { Error of } \\
\text { best guess }\end{array}$ \\
\hline Damage parameter & 0.0023 & 0.0023 & 0.0023 & $0.0 \%$ \\
\hline ETS & 3.10 & 3.10 & 3.10 & $0.0 \%$ \\
\hline Productiivity parameter & 0.0760 & 0.0760 & 0.0760 & $0.0 \%$ \\
\hline Carbon cycle parameter & 360.04 & 360.00 & 360.00 & $0.0 \%$ \\
\hline Decarbonization rate (\% per year) & $(0.0152)$ & $(0.0152)$ & $(0.0152)$ & $0.0 \%$ \\
\hline SCC, 2015 & 34.49 & 25.17 & 29.97 & $-13.1 \%$ \\
\hline SCC, 2020 & 40.60 & 29.66 & 35.75 & $-12.0 \%$ \\
\hline Temperature, $2050\left({ }^{\circ} \mathrm{C}\right)$ & 2.12 & 2.12 & 2.13 & $0.5 \%$ \\
\hline Temperature, $2100\left({ }^{\circ} \mathrm{C}\right)$ & 4.22 & 4.08 & 4.10 & $-2.6 \%$ \\
\hline Temperature, $2200\left({ }^{\circ} \mathrm{C}\right)$ & 6.56 & 6.21 & 6.71 & $2.4 \%$ \\
\hline Carbon concentrations, 2050 (GtC) & $1,205.56$ & $1,198.28$ & $1,176.61$ & $-2.4 \%$ \\
\hline Carbon concentrations, 2100 (GtC) & $2,065.30$ & $1,767.47$ & $1,760.67$ & $-14.7 \%$ \\
\hline Carbon concentrations, 2200 (GtC) & $2,741.84$ & $2,606.60$ & $2,650.64$ & $-3.3 \%$ \\
\hline Carbon concentrations, 2050 (ppm) & 565.99 & 562.57 & 552.40 & $-2.4 \%$ \\
\hline Carbon concentrations, 2100 (ppm) & 969.62 & 829.80 & 826.61 & $-14.7 \%$ \\
\hline Carbon concentrations, 2200 (ppm) & $1,287.25$ & $1,223.76$ & $1,244.43$ & $-3.3 \%$ \\
\hline World output, 2050 (trillions $2010 \$$ ) & 334.68 & 293.56 & 292.72 & $-12.5 \%$ \\
\hline World output, 2100 (trillions $2010 \$$ ) & $1,433.02$ & 766.29 & 758.81 & $-47.0 \%$ \\
\hline Emissions 2050 & 66.95 & 58.26 & 58.19 & $-13.1 \%$ \\
\hline Emissions 2100 & 109.42 & 71.10 & 70.91 & $-35.2 \%$ \\
\hline Emissions 2200 & 42.37 & 23.91 & 60.66 & $43.2 \%$ \\
\hline Damages, 2050 (\% output) & $1.03 \%$ & $0.88 \%$ & $1.03 \%$ & $-0.7 \%$ \\
\hline Damages, 2100 (\% output) & $4.30 \%$ & $3.22 \%$ & $3.82 \%$ & $-11.0 \%$ \\
\hline Damages, 2200 (\% output) & $8.34 \%$ & $5.75 \%$ & $7.35 \%$ & $-11.9 \%$ \\
\hline Emissions intensity, 2050 (CO2/\$) & 0.3503 & 0.3503 & 0.3503 & $0.0 \%$ \\
\hline Emissions intensity, $2100(\mathrm{CO} 2 / \$)$ & 0.1047 & 0.1012 & 0.1012 & $-3.3 \%$ \\
\hline Emissions intensity, 2200 (CO2/\$) & 0.0554 & 0.0511 & 0.0511 & $-7.7 \%$ \\
\hline Real interest rate, 2015 (\%/yr) & $5.1 \%$ & $5.1 \%$ & $5.1 \%$ & $-0.8 \%$ \\
\hline Real interest rate, 2100 (\%/yr) & $3.6 \%$ & $3.6 \%$ & $3.6 \%$ & $0.6 \%$ \\
\hline Objective (trillions, 2010\$) & $3,837.5$ & $4,513.3$ & $4,491.0$ & $17.0 \%$ \\
\hline
\end{tabular}

Table A-3. Error of best guess approach to DICE model

The last column shows the error from using a best guess rather than the uncertain version of the DICE-2016R model. The error is small where the distribution of the variable is close to symmetrical, but errors arise from skewed distributions. ${ }^{\mathrm{xiv}}$ 
\{?? The entry for "Productivity parameter" in Tables A-3, A-4, and A-5 contains a typo. ??\}

The detailed statistics of the major variables are as follows in Table A-4 for the baseline run and for the optimal case in Table A-5.

\begin{tabular}{|c|c|c|c|c|c|c|c|c|c|c|c|c|c|c|}
\hline Variable & Mean & St Dev & $1 \%$ ile & $5 \%$ ile & $10 \%$ ile & $25 \%$ ile & $50 \%$ ile & $75 \%$ ile & $90 \%$ ile & 95\%ile & 99\%ile & IQ range & Coef of Var & $\begin{array}{c}\text { DICE best } \\
\text { guess }\end{array}$ \\
\hline Damage parameter & 0.00227 & 0.00135 & 0.00061 & 0.00061 & 0.00061 & 0.00141 & 0.00227 & 0.00242 & 0.00464 & 0.00464 & 0.00464 & 0.00181 & 0.60 & 0.00227 \\
\hline ETS & 3.101 & 0.843 & 2.008 & 2.008 & 2.008 & 2.516 & 3.100 & 3.388 & 4.491 & 4.491 & 4.491 & 1.380 & 0.27 & 3.100 \\
\hline Productiivity parameter & 0.076 & 0.056 & $(0.002)$ & $(0.002)$ & $(0.002)$ & 0.043 & 0.076 & 0.098 & 0.165 & 0.165 & 0.165 & 0.101 & 0.74 & 0.076 \\
\hline Carbon cycle parameter & 360.0 & 97.0 & 233.6 & 233.6 & 233.6 & 293.0 & 360.0 & 394.4 & 519.3 & 519.3 & 519.3 & 160.8 & 0.27 & 360.0 \\
\hline Decarbonization rate (\% per year) & $-1.5 \%$ & $0.3 \%$ & $-2.0 \%$ & $-2.0 \%$ & $-2.0 \%$ & $-1.7 \%$ & $-1.5 \%$ & $-1.3 \%$ & $-1.1 \%$ & $-1.1 \%$ & $-1.1 \%$ & $0.7 \%$ & -0.21 & $-1.5 \%$ \\
\hline SCC, 2015 & 34.5 & 32.5 & 3.4 & 5.0 & 7.1 & 13.0 & 25.2 & 44.3 & 72.6 & 99.8 & 156.1 & 39.3 & 0.94 & 29.97 \\
\hline SCC, 2020 & 40.6 & 37.4 & 4.2 & 6.1 & 8.3 & 15.5 & 29.7 & 52.5 & 85.5 & 116.1 & 180.8 & 46.4 & 0.92 & 35.75 \\
\hline Temperature, $2050\left({ }^{\circ} \mathrm{C}\right)$ & 2.12 & 0.29 & 1.50 & 1.64 & 1.72 & 1.90 & 2.12 & 2.33 & 2.50 & 2.60 & 2.74 & 0.69 & 0.14 & 2.13 \\
\hline Temperature, $2100\left({ }^{\circ} \mathrm{C}\right)$ & 4.22 & 1.12 & 2.27 & 2.64 & 2.88 & 3.38 & 4.08 & 4.88 & 5.80 & 6.33 & 7.16 & 2.24 & 0.26 & 4.10 \\
\hline Temperature, $2200\left({ }^{\circ} \mathrm{C}\right)$ & 6.56 & 2.29 & 2.66 & 3.23 & 3.76 & 4.80 & 6.21 & 8.12 & 9.63 & 10.92 & 12.29 & 4.89 & 0.35 & 6.71 \\
\hline Carbon concentrations, 2050 (GtC) & 1,206 & 122 & 978 & 1,021 & 1,057 & 1,112 & 1,198 & 1,287 & 1,371 & 1,435 & 1,506 & 267 & 0.10 & 1,177 \\
\hline Carbon concentrations, 2100 (GtC) & 2,065 & 880 & 1,086 & 1,194 & 1,263 & 1,436 & 1,767 & 2,265 & 3,651 & 3,956 & 4,355 & 1,071 & 0.43 & 1,761 \\
\hline Carbon concentrations, 2200 (GtC) & 2,742 & 1,116 & 1,114 & 1,247 & 1,338 & 1,691 & 2,607 & 3,828 & 4,311 & 4,509 & 4,751 & 2,581 & 0.41 & 2,651 \\
\hline Carbon concentrations, $2050(\mathrm{ppm})$ & 566 & 57 & 459 & 479 & 496 & 522 & 563 & 604 & 644 & 674 & 707 & 267 & 0.10 & 552 \\
\hline Carbon concentrations, $2100(\mathrm{ppm})$ & 970 & 413 & 510 & 561 & 593 & 674 & 830 & 1,063 & 1,714 & 1,857 & 2,045 & 1,071 & 0.43 & 827 \\
\hline Carbon concentrations, 2200 (ppm) & 1,287 & 524 & 523 & 586 & 628 & 794 & 1,224 & 1,797 & 2,024 & 2,117 & 2,231 & 2,581 & 0.41 & 1,244 \\
\hline World output, 2050 (trillions 2010 \$) & 334.7 & 170.1 & 151.9 & 155.2 & 156.5 & 221.7 & 293.6 & 358.4 & 650.4 & 655.9 & 659.9 & 203.2 & 0.51 & 292.7 \\
\hline World output, 2100 (trillions $2010 \$$ ) & $1,433.0$ & $1,660.0$ & 160.0 & 167.7 & 171.0 & 393.6 & 766.3 & $1,231.6$ & $4,759.1$ & $4,982.8$ & $5,139.2$ & $1,063.9$ & 1.16 & 758.8 \\
\hline Emissions 2050 & 66.95 & 35.04 & 26.21 & 29.18 & 31.04 & 41.72 & 58.26 & 75.54 & 129.27 & 138.36 & 152.28 & 46.36 & 0.52 & 58.19 \\
\hline Emissions 2100 & 109.42 & 105.17 & 10.55 & 13.60 & 15.69 & 32.21 & 71.10 & 131.31 & 311.76 & 326.28 & 335.65 & 117.71 & 0.96 & 70.91 \\
\hline Emissions 2200 & 42.37 & 46.24 & 0.00 & 0.00 & 0.00 & 5.45 & 23.91 & 65.02 & 116.20 & 145.93 & 156.45 & 65.02 & 1.09 & 60.66 \\
\hline Damages, 2050 (\% output) & $1.03 \%$ & $0.70 \%$ & $0.17 \%$ & $0.22 \%$ & $0.27 \%$ & $0.51 \%$ & $0.88 \%$ & $1.36 \%$ & $2.07 \%$ & $2.52 \%$ & $3.13 \%$ & $1.13 \%$ & 0.67 & $1.03 \%$ \\
\hline Damages, 2100 (\% output) & $4.30 \%$ & $3.66 \%$ & $0.43 \%$ & $0.70 \%$ & $0.95 \%$ & $1.72 \%$ & $3.22 \%$ & $5.62 \%$ & $9.03 \%$ & $11.51 \%$ & $18.21 \%$ & $4.92 \%$ & 0.85 & $3.82 \%$ \\
\hline Damages, 2200 (\% output) & $8.34 \%$ & $7.94 \%$ & $0.59 \%$ & $1.08 \%$ & $1.57 \%$ & $2.92 \%$ & $5.75 \%$ & $10.98 \%$ & $18.03 \%$ & $24.86 \%$ & $37.79 \%$ & $9.89 \%$ & 0.95 & $7.35 \%$ \\
\hline Emissions intensity, 2050 (CO2/\$) & 0.350 & 0.000 & 0.350 & 0.350 & 0.350 & 0.350 & 0.350 & 0.350 & 0.350 & 0.350 & 0.350 & 0.000 & 0.00 & 0.350 \\
\hline Emissions intensity, $2100(\mathrm{CO} / \$)$ & 0.105 & 0.027 & 0.068 & 0.068 & 0.068 & 0.088 & 0.101 & 0.118 & 0.148 & 0.148 & 0.148 & 0.050 & 0.26 & 0.101 \\
\hline Emissions intensity, 2200 (CO2/\$) & 0.055 & 0.022 & 0.028 & 0.028 & 0.028 & 0.041 & 0.051 & 0.065 & 0.092 & 0.092 & 0.092 & 0.037 & 0.40 & 0.051 \\
\hline Real interest rate, 2015 (\%/yr) & $5.1 \%$ & $1.2 \%$ & $3.3 \%$ & $3.5 \%$ & $3.6 \%$ & $4.4 \%$ & $5.1 \%$ & $5.6 \%$ & $7.0 \%$ & $7.1 \%$ & $7.1 \%$ & $2.1 \%$ & 0.23 & $5.1 \%$ \\
\hline Real interest rate, $2100(\% / y r)$ & $3.6 \%$ & $1.6 \%$ & $1.3 \%$ & $1.4 \%$ & $1.4 \%$ & $2.6 \%$ & $3.6 \%$ & $4.3 \%$ & $6.1 \%$ & $6.3 \%$ & $6.4 \%$ & $3.0 \%$ & 0.44 & $3.6 \%$ \\
\hline Objective (trillions, 2010\$) & $3,837.5$ & $2,977.5$ & $-1,394.2$ & $-1,167.1$ & $-1,072.7$ & $2,554.3$ & $4,513.3$ & $5,578.5$ & $7,735.1$ & $7,769.6$ & $7,793.5$ & $6,745.6$ & 0.78 & $4,491.0$ \\
\hline
\end{tabular}

Table A-4. Statistics of major variables from uncertainty analysis for the baseline run. "DICE best guess" is the best guess or standard DICE model. ${ }^{\mathrm{xv}}$ 


\begin{tabular}{|c|c|c|c|c|c|c|c|c|c|c|c|c|c|c|}
\hline Variable & Mean & St Dev & $1 \%$ ile & $5 \%$ ile & $10 \%$ ile & $25 \%$ ile & $50 \%$ ile & $75 \%$ ile & $90 \%$ ile & 95\%ile & $99 \%$ ile & IQ range & Coef of Var & $\begin{array}{c}\text { DICE best } \\
\text { guess }\end{array}$ \\
\hline Damage parameter & 0.00227 & 0.00135 & 0.00061 & 0.00061 & 0.00061 & 0.00141 & 0.00227 & 0.00242 & 0.00464 & 0.00464 & 0.00464 & 0.00181 & 0.60 & 0.00227 \\
\hline ETS & 3.101 & 0.843 & 2.008 & 2.008 & 2.008 & 2.516 & 3.100 & 3.388 & 4.491 & 4.491 & 4.491 & 1.380 & 0.27 & 3.100 \\
\hline Productiivity parameter & 0.076 & 0.056 & $(0.002)$ & $(0.002)$ & $(0.002)$ & 0.043 & 0.076 & 0.098 & 0.165 & 0.165 & 0.165 & 0.101 & 0.74 & 0.076 \\
\hline Carbon cycle parameter & 360.0 & 97.0 & 233.6 & 233.6 & 233.6 & 293.0 & 360.0 & 394.4 & 519.3 & 519.3 & 519.3 & 160.8 & 0.27 & 360.0 \\
\hline Decarbonization rate (\% per year) & $-1.5 \%$ & $0.3 \%$ & $-2.0 \%$ & $-2.0 \%$ & $-2.0 \%$ & $-1.7 \%$ & $-1.5 \%$ & $-1.3 \%$ & $-1.1 \%$ & $-1.1 \%$ & $-1.1 \%$ & $0.7 \%$ & -0.21 & $-1.5 \%$ \\
\hline SCC, 2015 & 32.5 & 28.6 & 3.4 & 5.0 & 7.1 & 13.1 & 24.3 & 42.1 & 66.8 & 90.5 & 141.0 & 37.0 & 0.88 & 29.56 \\
\hline SCC, 2020 & 38.3 & 32.7 & 4.3 & 6.2 & 8.4 & 15.5 & 29.2 & 50.1 & 78.2 & 104.0 & 161.4 & 44.0 & 0.85 & 35.36 \\
\hline Temperature, $2050\left({ }^{\circ} \mathrm{C}\right)$ & 2.03 & 0.27 & 1.45 & 1.59 & 1.67 & 1.83 & 2.03 & 2.22 & 2.39 & 2.48 & 2.64 & 0.64 & 0.13 & 2.04 \\
\hline Temperature, $2100\left({ }^{\circ} \mathrm{C}\right)$ & 3.50 & 0.75 & 2.11 & 2.41 & 2.59 & 2.96 & 3.43 & 3.95 & 4.47 & 4.85 & 5.68 & 1.55 & 0.21 & 3.50 \\
\hline Temperature, $2200\left({ }^{\circ} \mathrm{C}\right)$ & 4.36 & 1.18 & 2.38 & 2.75 & 2.99 & 3.51 & 4.18 & 5.00 & 5.94 & 6.63 & 7.80 & 2.25 & 0.27 & 4.18 \\
\hline Carbon concentrations, 2050 (GtC) & 1,133 & 114 & 913 & 957 & 989 & 1,048 & 1,125 & 1,208 & 1,285 & 1,335 & 1,422 & 251 & 0.10 & 1,104 \\
\hline Carbon concentrations, 2100 (GtC) & 1,427 & 402 & 941 & 1,018 & 1,073 & 1,179 & 1,331 & 1,548 & 1,839 & 2,174 & 3,098 & 530 & 0.28 & 1,348 \\
\hline Carbon concentrations, 2200 (GtC) & 1,461 & 449 & 924 & 1,006 & 1,063 & 1,177 & 1,345 & 1,604 & 1,991 & 2,348 & 3,222 & 598 & 0.31 & 1,297 \\
\hline Carbon concentrations, 2050 (ppm) & 532 & 54 & 428 & 449 & 464 & 492 & 528 & 567 & 603 & 627 & 668 & 118 & 0.05 & 518 \\
\hline Carbon concentrations, 2100 (ppm) & 670 & 189 & 442 & 478 & 504 & 554 & 625 & 727 & 864 & 1,020 & 1,455 & 249 & 0.13 & 633 \\
\hline Carbon concentrations, 2200 (ppm) & 686 & 211 & 434 & 472 & 499 & 552 & 631 & 753 & 935 & 1,102 & 1,513 & 281 & 0.14 & 609 \\
\hline World output, 2050 (trillions 2010 \$) & 335.0 & 170.4 & 152.0 & 155.1 & 156.5 & 221.8 & 293.6 & 358.3 & 650.5 & 655.7 & 659.8 & 203.2 & 0.51 & 292.8 \\
\hline World output, 2100 (trillions 2010 \$) & $1,495.9$ & $1,753.0$ & 163.8 & 168.9 & 171.6 & 397.8 & 771.8 & $1,234.6$ & $4,929.7$ & $4,997.9$ & $5,139.4$ & $1,065.7$ & 1.17 & 765.8 \\
\hline Emissions 2050 & 45.58 & 25.49 & 11.59 & 17.20 & 20.61 & 27.18 & 39.20 & 55.69 & 84.55 & 101.76 & 123.92 & 38.49 & 0.56 & 39.65 \\
\hline Emissions 2100 & 20.62 & 34.06 & 0.00 & 0.00 & 0.00 & 0.00 & 11.11 & 25.75 & 50.18 & 72.88 & 189.27 & 25.75 & 1.65 & 14.08 \\
\hline Emissions 2200 & 4.53 & 9.30 & 0.00 & 0.00 & 0.00 & 0.00 & 0.00 & 5.22 & 13.08 & 23.12 & 47.27 & 5.22 & 2.05 & - \\
\hline Damages, 2050 (\% output) & $0.93 \%$ & $0.58 \%$ & $0.16 \%$ & $0.22 \%$ & $0.27 \%$ & $0.48 \%$ & $0.82 \%$ & $1.22 \%$ & $1.78 \%$ & $2.12 \%$ & $2.57 \%$ & $1.00 \%$ & 0.63 & $0.94 \%$ \\
\hline Damages, 2100 (\% output) & $2.58 \%$ & $1.41 \%$ & $0.40 \%$ & $0.65 \%$ & $0.87 \%$ & $1.47 \%$ & $2.42 \%$ & $3.45 \%$ & $4.48 \%$ & $5.22 \%$ & $6.60 \%$ & $2.81 \%$ & 0.55 & $2.78 \%$ \\
\hline Damages, 2200 (\% output) & $3.48 \%$ & $1.79 \%$ & $0.56 \%$ & $0.99 \%$ & $1.36 \%$ & $2.19 \%$ & $3.23 \%$ & $4.47 \%$ & $5.91 \%$ & $6.82 \%$ & $8.84 \%$ & $3.48 \%$ & 0.51 & $3.75 \%$ \\
\hline Emissions intensity, 2050 (CO2/\$) & 0.350 & 0.000 & 0.350 & 0.350 & 0.350 & 0.350 & 0.350 & 0.350 & 0.350 & 0.350 & 0.350 & 0.000 & 0.00 & 0.350 \\
\hline Emissions intensity, 2100 (CO2/\$) & 0.105 & 0.027 & 0.068 & 0.068 & 0.068 & 0.088 & 0.101 & 0.118 & 0.148 & 0.148 & 0.148 & 0.050 & 0.26 & 0.101 \\
\hline Emissions intensity, 2200 (CO2/\$) & 0.055 & 0.022 & 0.028 & 0.028 & 0.028 & 0.041 & 0.051 & 0.065 & 0.092 & 0.092 & 0.092 & 0.037 & 0.40 & 0.051 \\
\hline Real interest rate, 2015 (\%/yr) & $5.1 \%$ & $1.2 \%$ & $3.4 \%$ & $3.5 \%$ & $3.6 \%$ & $4.4 \%$ & $5.1 \%$ & $5.6 \%$ & $7.0 \%$ & $7.1 \%$ & $7.1 \%$ & $2.1 \%$ & 0.23 & $5.1 \%$ \\
\hline Real interest rate, 2100 (\%/yr) & $3.7 \%$ & $1.7 \%$ & $1.4 \%$ & $1.4 \%$ & $1.4 \%$ & $2.7 \%$ & $3.7 \%$ & $4.4 \%$ & $6.5 \%$ & $6.5 \%$ & $6.6 \%$ & $3.0 \%$ & 0.46 & $3.6 \%$ \\
\hline Objective (trillions, 2010\$) & $3,872.6$ & $2,981.5$ & $-1,306.7$ & $-1,139.4$ & $-1,061.8$ & $2,591.5$ & $4,533.1$ & $5,587.2$ & $7,755.7$ & $7,776.0$ & $7,794.0$ & $6,726.7$ & 0.77 & $4,519.1$ \\
\hline
\end{tabular}

Table A-5. Statistics of major variables from uncertainty analysis for the optimal run.xvi 


\begin{tabular}{|c|c|c|c|c|c|c|c|c|c|c|c|c|c|c|c|c|c|c|}
\hline Year & 2015 & 2020 & 2025 & 2030 & 2035 & 2040 & 2045 & 2050 & 2055 & 2060 & 2065 & 2070 & 2075 & 2080 & 2085 & 2090 & 2095 & 2100 \\
\hline Industrial Emissions GTCO2 per year & 35.7 & 39.4 & 42.9 & 46.4 & 49.6 & 52.7 & 55.6 & 58.2 & 60.6 & 62.7 & 64.6 & 66.3 & 67.7 & 68.8 & 69.7 & 70.4 & 70.8 & 70.9 \\
\hline Atmospheric concentration C (ppm) & 399.5 & 418.5 & 438.3 & 459.2 & 481.0 & 503.9 & 527.7 & 552.4 & 577.9 & 604.1 & 630.9 & 658.2 & 685.8 & 713.8 & 742.0 & 770.2 & 798.5 & 826.6 \\
\hline Atmospheric Temperature & 0.85 & 1.02 & 1.19 & 1.37 & 1.55 & 1.74 & 1.93 & 2.13 & 2.32 & 2.52 & 2.72 & 2.93 & 3.13 & 3.33 & 3.52 & 3.72 & 3.91 & 4.10 \\
\hline Output Net Net) & 105 & 125 & 147 & 172 & 199 & 228 & 259 & 293 & 329 & 367 & 408 & 451 & 497 & 544 & 595 & 647 & 702 & 759 \\
\hline Climate Damages fraction output & 0.0016 & 0.0023 & 0.0032 & 0.0042 & 0.0055 & 0.0069 & 0.0085 & 0.0103 & 0.0123 & 0.0145 & 0.0168 & 0.0194 & 0.0222 & 0.0251 & 0.0282 & 0.0314 & 0.0348 & 0.0382 \\
\hline Consumption Per Capita & 10.50 & 11.84 & 13.31 & 14.89 & 16.61 & 18.47 & 20.46 & 22.59 & 24.87 & 27.30 & 29.87 & 32.60 & 35.48 & 38.51 & 41.69 & 45.03 & 48.52 & 52.16 \\
\hline Carbon Price (per t CO2) & 2.00 & 2.21 & 2.44 & 2.69 & 2.97 & 3.28 & 3.62 & 4.00 & 4.42 & 4.88 & 5.38 & 5.94 & 6.56 & 7.25 & 8.00 & 8.83 & 9.75 & 10.77 \\
\hline Emissions Control Rate & 0.03 & 0.03 & 0.03 & 0.04 & 0.04 & 0.04 & 0.05 & 0.05 & 0.06 & 0.06 & 0.06 & 0.07 & 0.08 & 0.08 & 0.09 & 0.10 & 0.10 & 0.11 \\
\hline Social cost of carbon & 29.97 & 35.75 & 42.26 & 49.53 & 57.60 & 66.48 & 76.21 & 86.81 & 98.31 & 110.71 & 124.05 & 138.33 & 153.57 & 169.77 & 186.94 & 205.09 & 224.23 & 244.37 \\
\hline Interest Rate & 0.051 & 0.050 & 0.049 & 0.048 & 0.047 & 0.046 & 0.045 & 0.044 & 0.043 & 0.042 & 0.041 & 0.040 & 0.039 & 0.039 & 0.038 & 0.037 & 0.037 & 0.036 \\
\hline Population & 7,403 & 7,853 & 8,265 & 8,639 & 8,977 & 9,280 & 9,550 & 9,791 & 10,004 & 10,193 & 10,359 & 10,505 & 10,633 & 10,745 & 10,844 & 10,929 & 11,004 & 11,069 \\
\hline TFP & 5.12 & 5.54 & 5.98 & 6.44 & 6.93 & 7.45 & 7.98 & 8.54 & 9.12 & 9.73 & 10.36 & 11.01 & 11.68 & 12.38 & 13.10 & 13.84 & 14.60 & 15.38 \\
\hline Output gross,gross & 105 & 125 & 148 & 173 & 200 & 229 & 261 & 296 & 333 & 373 & 415 & 460 & 508 & 558 & 612 & 668 & 727 & 789 \\
\hline Change tfp & 0.076 & 0.074 & 0.072 & 0.071 & 0.069 & 0.067 & 0.065 & 0.064 & 0.062 & 0.061 & 0.059 & 0.058 & 0.056 & 0.055 & 0.054 & 0.052 & 0.051 & 0.050 \\
\hline Capital & 223 & 268 & 319 & 375 & 437 & 505 & 580 & 660 & 747 & 841 & 941 & 1,049 & 1,162 & 1,283 & 1,411 & 1,545 & 1,687 & 1,835 \\
\hline s & 0.26 & 0.26 & 0.25 & 0.25 & 0.25 & 0.25 & 0.25 & 0.24 & 0.24 & 0.24 & 0.24 & 0.24 & 0.24 & 0.24 & 0.24 & 0.24 & 0.24 & 0.24 \\
\hline 1 & 27.27 & 32.07 & 37.35 & 43.14 & 49.44 & 56.26 & 63.61 & 71.51 & 79.95 & 88.96 & 98.52 & 108.65 & 119.35 & 130.62 & 142.46 & 154.87 & 167.86 & 181.40 \\
\hline Y gross net & 105 & 125 & 147 & 172 & 199 & 228 & 259 & 293 & 329 & 367 & 408 & 451 & 497 & 544 & 595 & 647 & 702 & 759 \\
\hline damages & 0.17 & 0.29 & 0.47 & 0.73 & 1.09 & 1.58 & 2.21 & 3.04 & 4.08 & 5.39 & 6.99 & 8.94 & 11.26 & 14.02 & 17.24 & 20.98 & 25.28 & 30.18 \\
\hline damfrac & 0.0016 & 0.0023 & 0.0032 & 0.0042 & 0.0055 & 0.0069 & 0.0085 & 0.0103 & 0.0123 & 0.0145 & 0.0168 & 0.0194 & 0.0222 & 0.0251 & 0.0282 & 0.0314 & 0.0348 & 0.0382 \\
\hline abatement & 0.00 & 0.00 & 0.00 & 0.00 & 0.00 & 0.00 & 0.00 & 0.00 & 0.01 & 0.01 & 0.01 & 0.01 & 0.01 & 0.02 & 0.02 & 0.03 & 0.03 & 0.04 \\
\hline sigma & 0.35 & 0.32 & 0.30 & 0.28 & 0.26 & 0.24 & 0.22 & 0.21 & 0.19 & 0.18 & 0.17 & 0.15 & 0.14 & 0.13 & 0.13 & 0.12 & 0.11 & 0.10 \\
\hline Forcings & 2.46 & 2.74 & 3.01 & 3.29 & 3.57 & 3.84 & 4.12 & 4.39 & 4.66 & 4.92 & 5.18 & 5.44 & 5.69 & 5.93 & 6.16 & 6.39 & 6.61 & 6.82 \\
\hline Other Forcings & 0.50 & 0.53 & 0.56 & 0.59 & 0.62 & 0.65 & 0.68 & 0.71 & 0.74 & 0.76 & 0.79 & 0.82 & 0.85 & 0.88 & 0.91 & 0.94 & 0.97 & 1.00 \\
\hline Period utilty & 0.45 & 0.49 & 0.53 & 0.56 & 0.59 & 0.62 & 0.65 & 0.68 & 0.70 & 0.72 & 0.74 & 0.76 & 0.78 & 0.79 & 0.81 & 0.82 & 0.83 & 0.85 \\
\hline Consumption & 77.73 & 93.00 & 109.97 & 128.67 & 149.14 & 171.37 & 195.39 & 221.21 & 248.83 & 278.24 & 309.46 & 342.46 & 377.24 & 413.80 & 452.11 & 492.16 & 533.93 & 577.40 \\
\hline Objective & 4,491.07 & & & & & & & & & & & & & & & & & \\
\hline Land emissions & 2.60 & 2.30 & 2.04 & 1.80 & 1.59 & 1.41 & 1.25 & 1.11 & 0.98 & 0.87 & 0.77 & 0.68 & 0.60 & 0.53 & 0.47 & 0.42 & 0.37 & 0.33 \\
\hline Cumulative ind emissions & 400 & 449 & 502 & 561 & 624 & 692 & 764 & 840 & 919 & 1,002 & 1,087 & 1,175 & 1,266 & 1,358 & 1,452 & 1,547 & 1,643 & 1,739 \\
\hline Cumulative total emissions & 500 & 552 & 609 & 670 & 736 & 806 & 880 & 957 & 1,038 & 1,122 & 1,209 & 1,298 & 1,389 & 1,483 & 1,577 & 1,673 & 1,769 & 1,866 \\
\hline Atmospheric concentrations Gt & 851 & 891 & 934 & 978 & 1,025 & 1,073 & 1,124 & 1,177 & 1,231 & 1,287 & 1,344 & 1,402 & 1,461 & 1,520 & 1,580 & 1,641 & 1,701 & 1,761 \\
\hline Atmospheric concentrations ppm & 400 & 418 & 438 & 459 & 481 & 504 & 528 & 552 & 578 & 604 & 631 & 658 & 686 & 714 & 742 & 770 & 798 & 827 \\
\hline Total Emissions GTCO2 per year & 38 & 42 & 45 & 48 & 51 & 54 & 57 & 59 & 62 & 64 & 65 & 67 & 68 & 69 & 70 & 71 & 71 & 71 \\
\hline Atmospheric concentrations upper & 460 & 471 & 485 & 501 & 519 & 539 & 561 & 585 & 610 & 636 & 664 & 693 & 723 & 754 & 786 & 819 & 852 & 886 \\
\hline Atmospheric concentrations lower & 1,740 & 1,741 & 1,741 & 1,742 & 1,743 & 1,744 & 1,746 & 1,747 & 1,748 & 1,750 & 1,752 & 1,754 & 1,756 & 1,759 & 1,762 & 1,765 & 1,768 & 1,771 \\
\hline Atmospheric fraction since 1850 & 0.53 & 0.55 & 0.57 & 0.58 & 0.59 & 0.60 & 0.61 & 0.61 & 0.62 & 0.62 & 0.63 & 0.63 & 0.63 & 0.63 & 0.63 & 0.63 & 0.63 & 0.63 \\
\hline Atmospheric fraction since 2010 & - & 0.77 & 0.76 & 0.74 & 0.73 & 0.73 & 0.72 & 0.71 & 0.71 & 0.70 & 0.70 & 0.69 & 0.69 & 0.68 & 0.68 & 0.67 & 0.67 & 0.67 \\
\hline
\end{tabular}

Table A-6. Detailed results for baseline run by time periodxvii 


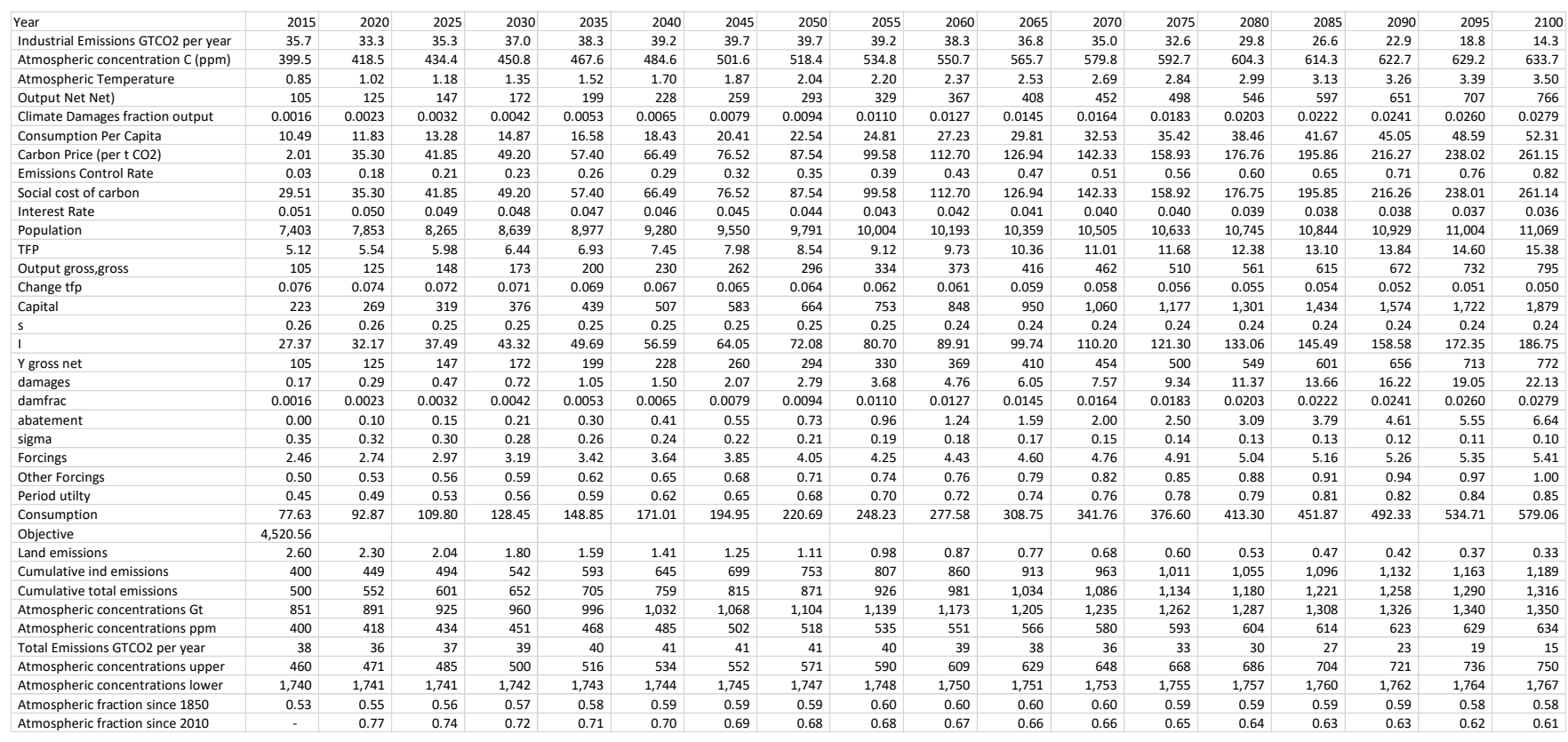

Table A-7. Detailed results for optimal run by time periodxviii 


\begin{tabular}{|c|c|c|c|c|c|c|c|c|c|c|c|c|c|}
\hline Variable & Mean & $\begin{array}{l}\text { Standard } \\
\text { deviation }\end{array}$ & $1 \%$ ile & $5 \%$ ile & 10\%ile & $25 \%$ ile & $50 \%$ ile & 75\%ile & $90 \%$ ile & 95\%ile & 99\%ile & IQ & $\begin{array}{c}\text { Coef of } \\
\text { Var }\end{array}$ \\
\hline SCC, 2015 & 28.65 & 20.84 & 3.31 & 5.39 & 7.38 & 13.45 & 23.76 & 37.99 & 55.95 & 70.69 & 96.71 & 32.60 & 0.73 \\
\hline SCC, 2020 & 33.25 & 23.74 & 3.66 & 6.30 & 8.62 & 15.81 & 27.87 & 44.19 & 64.53 & 80.10 & 111.82 & 37.89 & 0.71 \\
\hline Temperature, $2050\left({ }^{\circ} \mathrm{C}\right)$ & 1.63 & 0.25 & 1.12 & 1.25 & 1.31 & 1.45 & 1.65 & 1.81 & 1.99 & 2.00 & 2.15 & 0.56 & 0.15 \\
\hline Temperature, $2100\left({ }^{\circ} \mathrm{C}\right)$ & 2.12 & 0.49 & 1.19 & 1.42 & 1.48 & 1.76 & 2.13 & 2.50 & 2.80 & 2.90 & 3.20 & 1.07 & 0.23 \\
\hline Temperature, $2200\left({ }^{\circ} \mathrm{C}\right)$ & 1.76 & 0.91 & 0.04 & 0.20 & 0.42 & 1.13 & 1.83 & 2.43 & 2.91 & 3.20 & 3.77 & 2.23 & 0.52 \\
\hline Carbon concentrations, 2050 (ppm) & 872.06 & 66.75 & 774.07 & 775.42 & 775.75 & 835.56 & 864.96 & 912.16 & 972.80 & 973.27 & 973.75 & 136.74 & 0.08 \\
\hline Carbon concentrations, 2100 (ppm) & 863.47 & 73.42 & 753.32 & 754.48 & 754.75 & 825.06 & 857.82 & 908.74 & 971.77 & 972.22 & 972.67 & 154.27 & 0.09 \\
\hline Carbon concentrations, 2200 (ppm) & 857.93 & 73.14 & 748.32 & 749.44 & 749.70 & 819.66 & 852.23 & 902.93 & 965.91 & 966.35 & 966.80 & 153.49 & 0.09 \\
\hline World output, 2050 (trillions 2010 \$) & 305.99 & 123.49 & 157.21 & 158.11 & 158.65 & 223.06 & 279.22 & 351.93 & 518.49 & 520.14 & 521.66 & 193.82 & 0.40 \\
\hline World output, 2100 (trillions 2010 \$) & $1,219.13$ & $1,123.53$ & 194.96 & 197.78 & 199.31 & 454.27 & 776.86 & $1,343.30$ & $3,343.80$ & $3,363.75$ & $3,378.19$ & $1,145.52$ & 0.92 \\
\hline
\end{tabular}

Table A-8. Detailed results for maximum abatement run ${ }^{x i x}$ 


\begin{tabular}{|c|c|c|c|c|c|c|c|c|}
\hline \multirow{2}{*}{$\begin{array}{l}\text { Learning } \\
\text { structure }\end{array}$} & \multicolumn{8}{|c|}{ Optimal carbon prices } \\
\hline & 2015 & 2020 & 2025 & 2030 & 2035 & 2040 & 2045 & 2050 \\
\hline Learn then act & 34.15 & 39.80 & 45.52 & 51.57 & 58.18 & 65.53 & 73.78 & 83.05 \\
\hline Act then learn & 36.10 & 42.10 & 48.72 & 55.19 & 62.27 & 70.15 & 79.00 & 88.94 \\
\hline
\end{tabular}

Note that Act then learn prices are not state contingent for 2015-2050.

Table A-9. Optimal carbon prices with and without learningxx 